Grigorios Kotronoulas, Nora Kearney, Roma Maguire, University of Surrey, Guildford; Alison Harrow, Dundee Cancer Centre; David Di Domenico, Stephen MacGillivray, University of Dundee, Dundee; Suzanne Croy, Dementia Services Developmen Centre, University of Stirling, Stirling, United Kingdom

Published online ahead of print at www.jco.org on April 7, 2014

Authors' disclosures of potential conflicts of interest and author contributions are found at the end of this article.

Corresponding author: Grigorios Kotronoulas, $\mathrm{PhD}, \mathrm{MSc}, \mathrm{BSN}$, School of Health and Social Care, University of Surrey, Duke of Kent Building, Guildford, Surrey,

GU2 7TE, United Kingdom; e-mail: g.kotronoulas@surrey.ac.uk.

(c) 2014 by American Society of Clinica Oncology

0732-183X/14/3214w-1480w/\$20.00

DOI: $10.1200 / J C O .2013 .53 .5948$

\title{
What Is the Value of the Routine Use of Patient-Reported Outcome Measures Toward Improvement of Patient Outcomes, Processes of Care, and Health Service Outcomes in Cancer Care? A Systematic Review of Controlled Trials
}

Grigorios Kotronoulas, Nora Kearney, Roma Maguire, Alison Harrow, David Di Domenico, Suzanne Croy, and Stephen MacGillivray

\section{$\begin{array}{llllllll}\text { A } & \text { B } & \text { S } & \text { T } & \text { R } & \text { A } & \text { C } & \text { T }\end{array}$}

\section{Purpose}

The systematic use of patient-reported outcome measures (PROMs) has been advocated as an effective way to standardize cancer practice. Yet, the question of whether PROMs can lead to actual improvements in the quality of patient care remains under debate. This review examined whether inclusion of PROM in routine clinical practice is associated with improvements in patient outcomes, processes of care, and health service outcomes during active anticancer treatment.

\section{Methods}

A systematic review of five electronic databases (Medline, EMBASE, CINAHL [Cumulative Index to Nursing and Allied Health Literature], PsycINFO, and Psychology and Behavioral Sciences Collection [PBSC]) was conducted from database inception to May 2012 to locate randomized and nonrandomized controlled trials of patients receiving active anticancer treatment or supportive care irrespective of type of cancer.

\section{Results}

Based on prespecified eligibility criteria, we included 26 articles that reported on 24 unique controlled trials. Wide variability in the design and use of interventions delivered, outcomes evaluated, and cancer- and modality-specific context was apparent. Health service outcomes were only scarcely included as end points. Overall, the number of statistically significant findings were limited and PROMs' intervention effect sizes were predominantly small-to-moderate.

\section{Conclusion}

The routine use of PROMs increases the frequency of discussion of patient outcomes during consultations. In some studies, PROMs are associated with improved symptom control, increased supportive care measures, and patient satisfaction. Additional effort is required to ensure patient adherence, as well as additional support to clinicians who will respond to patient concerns and issues, with clear system guidelines in place to guide their responses. More research is required to support PROM cost-benefit in terms of patient safety, clinician burden, and health services usage.

\section{J Clin Oncol 32:1480-1501. (C) 2014 by American Society of Clinical Oncology}

\section{INTRODUCTION}

Anticancer treatments have brought about definite advances in patient survival rates. ${ }^{1}$ However, treatment is associated with significant toxicity that is potentially life-threatening, ${ }^{1}$ and can often result in poor treatment adherence, impaired quality of life (QoL), and mortality. ${ }^{2,3}$ Systematic monitoring is crucial to detect problems, to address needs of patients, and to plan care. ${ }^{4}$ Using patient-reported outcome measures (PROMs), "measurements of any aspect of a patient's health status that come directly from the patient," facilitates a systematic and com- prehensive approach to patient assessment and identifies problems that are often overlooked within routine practice. Regularly collecting PROM data is an effective way to standardize practice and improve patient management. ${ }^{4}$ Nevertheless, the question of whether PROMs can improve the quality of patient care, and whether this relates both to health professional engagement with them and to the system guidelines in place to guide response, remains under debate. Given the costs associated with collecting PROMs, evidence of their effect on patient outcomes (POs), processes of care (PoCs), and/or health service outcomes (HSOs) is needed. 
Previous reviews have concluded some clinically meaningful, but not always statistically significant, effects on the use of PROMs in clinical practice. $^{5-11}$ Only two of these reviews ${ }^{9,11}$ were specific to cancer care and differed in terms of objectives, comprehensiveness, and quality. Taking into consideration the lack of clarity around the use of PROMs in cancer care, we conducted a comprehensive systematic review of all available controlled trials (CTs) to examine whether routine use of PROMs by health care professionals (HPs) can improve the quality of care patients receive during active anticancer treatment. The value of PROM use was examined through detection of positive effects on POs, PoCs, and HSOs, as suggested by statistical/clinical changes.

\section{METHODS}

We searched five electronic databases (Medline, EMBASE, CINAHL [Cumulative Index to Nursing and Allied Health Literature], PsycINFO, and PBSC) from database inception to May 2012, using a systematic strategy that was devised and refined through an iterative process (Appendix Table A1 [onlineonly]). Additional articles were identified through previous topical reviews. ${ }^{5-11}$ We also examined reference lists of the articles retained for any studies that might have been overlooked. Where necessary, we contacted study authors to provide clarification on characteristics of the study samples included. We followed the Preferred Reporting Items for Systematic Reviews and Meta-Analyses (PRISMA) guidelines where applicable. ${ }^{12}$

\section{Study Selection Criteria}

Trials were deemed eligible if they were primary or secondary reports of CTs testing PROM interventions in which PROM-generated feedback was made available to HPs or patients to improve quality of patient care; involved adult patients ( $>18$ years old) with cancer, irrespective of disease stage, who received any type of active anticancer treatment or supportive care, even if only part of the sample received active treatment/care but percentages were reported; were randomized CTs (RCTs) or non-RCTs; and were published in the English language with readily available abstracts. Trials were excluded if they evaluated PROMs as part of broader psychobehavioral interventions, in which PROMs were only used to evaluate intervention effectiveness; investigated the effects of a medicinal product; were conducted with survivors of cancer who were not actively receiving anticancer treatment; tested the psychometric properties of PROMs; or involved children with cancer, or survivors of childhood cancers.

\section{Study Selection and Data Extraction Procedures}

Study selection involved two stages: an initial title and abstract screening with eligibility evaluation performed by two screening groups that independently screened the retrieved records against selection criteria, and retrieving potentially eligible full-text articles, which were independently evaluated for eligibility by five reviewers. Selection of the final sample of studies was discussed until a consensus was reached. Five reviewers extracted data using forms that were specifically developed for this review, pilot tested the forms on three randomly selected studies, and refined the forms accordingly.

\section{Risk of Bias and Methodologic Quality Evaluation}

We used the Cochrane Collaboration Risk of Bias Tool ${ }^{13}$ to evaluate six different domains of a CT: adequacy of sequence generation, concealment of allocation, blinding, completeness of follow-up, freedom from reporting bias, and other forms of bias. We evaluated each domain of bias as low risk, high risk, or unclear. Three reviewers assessed five articles each, and a fourth reviewer cross-checked the evaluations until a consensus was reached. Reviewers were not blinded to authors, institutions, or journals of publication.

\section{Outcome Evaluation}

Based on previous topical reviews, ${ }^{5-11}$ three major outcome categories were formed: POs (ie, health status/well-being/functioning; symptom burden/ distress; health-related QoL; psychological distress), PoCs (ie, patient satisfac- tion with treatment/care/consultation; patient behaviors/actions/adherence; patient-HP communication; patient-HP concordance in assessments; HP engagement in assessment), and HSOs (ie, patient safety; cost-effectiveness; number of contacts with clinicians; patient resources/services use). We anticipated that not all CTs would report on every outcome category or on every outcome within a specific category.

\section{Synthesis of Results and Determination of Effect Sizes}

Individual outcomes were classified according to prespecified major outcome categories, and findings were narratively synthesized. Prevalence (\%) of studies examining each individual outcome and major categories was examined and plotted. Because of variability in the patient populations, outcomes assessed, outcome PROMs used, and reporting of results, we deemed a meta-analysis was not feasible. However, where enough data were available, effect sizes (ES; Cohen's $d$ ) and 95\% CIs were estimated based on mean postintervention total scores of outcome measures or percentages of patients reporting specific outcomes based on specific formulas. ${ }^{14,15}$ By convention, ES where $d \geq 0.2$ were considered small, $d \geq 0.5$ were moderate, and $d \geq 0.8$ were large. $^{16}$

\section{RESULTS}

\section{Search Results and Study Characteristics}

Initial searches retrieved 4,997 references from electronic databases and 18 from previous published literature reviews. ${ }^{5-11}$ Twenty-six articles ${ }^{17-42}$ reporting on 24 unique CTs fulfilled eligibility criteria and were included in a qualitative synthesis (Fig 1). All but four trials ${ }^{18,24,34,36}$ were RCTs, and 16 adopted a longitudinal study design (Table 1). Patient study samples varied widely in size (median, 194 individuals; range, 48 to 1,134 individuals; for a total of 6,279 individuals). HP samples varied similarly (median, 22 HPs; range, four to $262 \mathrm{HPs}$; total, $\mathrm{n}=713$ ), but they were reported in only 11 trials. Nine CTs tested interventions designed specifically for patients with breast,$~^{20,22,26,27}$ lung, ${ }^{20,29,30,33,34}$ or hematologic malignancies. ${ }^{32}$ Seventeen CTs tested interventions delivered in the outpatient/ambulatory setting. Only two RCTs targeted patients with early-stage cancers. ${ }^{19,22}$ Thirty-seven percent to $100 \%$ of patients were receiving active anticancer treatments during study participation, and these treatments were most frequently chemotherapy or radiotherapy.

In terms of intervention design, patients in the control group either received usual care only ${ }^{19,21,28,34,36,41,42}$ or completed PROMs similar to that of the experimental group, but feedback remained unavailable to HP. ${ }^{17,18,24,26,30-33,37,40}$ Only one three-arm RCT combined these two alternative conditions in the same design. ${ }^{35,38,39}$ In the more diverse CTs, PROMs were completed at home by the experimental group but were not administered to patients in the control group ${ }^{25,29}$; were completed by all participants, but PROM summaries of the experimental group were only placed in the medical records or sent to $\mathrm{HPs}^{20,23}$; or were completed by patients in the experimental group only to direct further intervention based on distress expressed by a subset of the group. ${ }^{20,22,27}$ In only five CTs did HPs follow specific guidelines to guide response to PROM feedback. ${ }^{20,22,23,26,28}$

Twenty-nine PROMs were administered in the reviewed trials to help deliver the interventions (Appendix Table A2). Eleven CTs relied on only one intervention PROM, seven incorporated two PROMs, and six CTs used three or more instruments. ${ }^{17,18,23,24,28,42}$ The most frequently used PROM was the European Organisation for Research and Treatment of Cancer Quality of Life Questionnaire C30 (EORTC QLQ-C30; $\mathrm{n}=11$ ). Other PROMs focused on symptom prevalence and severity $(\mathrm{n}=11)$, supportive care needs $(\mathrm{n}=8)$, QoL issues $(n=5)$, or sources of distress $(n=3)$. The PROMs were administered on media including electronic platforms $(n=11)$, paper-and-pencil tools in clinic $(\mathrm{n}=12)$, take-home log books $(\mathrm{n}=3)$, and mailed assessments and/or telephone interviews ( $\mathrm{n}=7$; Table 1$)$.

\section{Risk of Bias Within and Across Studies}

Two RCTs were rated as low risk in five of the seven bias categories. ${ }^{26,29}$ Yet, bias in the design and/or reporting was present in all of the included trials (Table 2), regardless of whether patients were randomly assigned to the study 


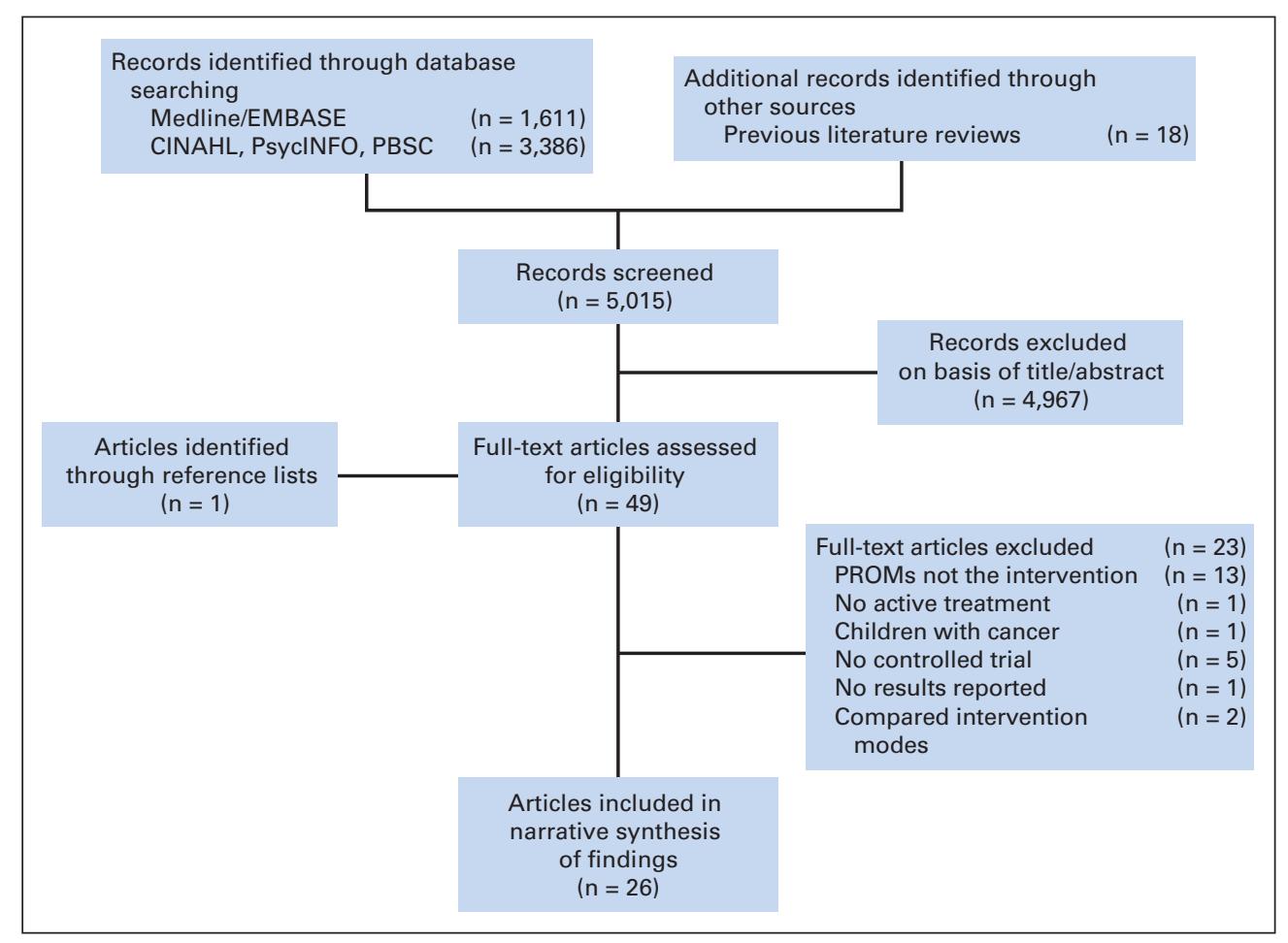

Fig 1. Diagram of the study selection process according to Preferred Reporting Items for Systematic Reviews and Meta-Analyses guidelines. ${ }^{12,43} \mathrm{CINAHL}$, Cumulative Index to Nursing and Allied Health Literature; PBSC, Psychology and Behavioral Sciences Collection; PROMs, patient-reported outcome measures.

condition. Only seven RCTs were rated as low risk on both the randomassignment generation process and allocation-concealment bias. ${ }^{17,20,26-29,41}$ Conversely, all non-RCTs were consistently rated as high risk. With the exception of three RCTs, ${ }^{21,22,40}$ performance bias was rated as high for all CTs given that blinding on the HP level was not feasible. With the exception of seven $\mathrm{CTs},{ }^{18,25,28-30,40,41}$ risk of detection bias was also deemed high or unclear. Ten CTs were rated as high risk regarding attrition-related bias. ${ }^{18-20,24,27,33,35,38-42}$ Selective outcome reporting bias was predominantly unclear $(\mathrm{n}=18 ; 75 \%)$. Additional sources of bias interfered with 15 CTs. Most frequently, authors were unclear as to whether HPs who received patient feedback actually used it during consultations.

\section{Outcomes Evaluation}

POs and/or PoCs were reported as primary outcomes in 21 CTs (87.5\%) and 19 CTs (79.2\%), respectively; however, intervention effects on HSOs were only scarcely investigated (Table 2 and Table 3)..$^{2,22,27,30,42}$ Eighteen CTs evaluated the effects of interventions in the long term $(>8$ weeks), with follow-up assessments ranging in number from two to four or more that were conducted for up to 12 months (but mainly $\leq 6$ months) after baseline assessment.

\section{Patient Outcomes}

Physical symptoms. Overall, positive effects with reduced symptom prevalence or severity were reported in seven CTs (six RCTs), mainly clinically and less frequently statistically significant. ES ranged widely and were mainly small-tomoderate in terms of intervention effects on physical symptom prevalence $(d=$ 0.01 to 0.75 ), physical symptom severity ( $d=0.0$ to 0.44 ), psychological symptom prevalence $(d=0.07$ to 0.15$)$, psychological symptom severity $(d=0.01$ to 0.30$)$, or psychological symptom distress ( $d=0.09$ to 0.42 ; Appendix Table A3). Across $\mathrm{CTs}$, patients in the experimental group reported greater reductions in symptomthreshold events and symptom interference with functioning, ${ }^{40}$ severity of menopausal symptoms and sexual dysfunction, ${ }^{22}$ frequency of constipation and vomiting, ${ }^{25}$ incidence of pain ${ }^{37}$ or fatigue, ${ }^{41}$ debilitating symptoms, ${ }^{18}$ and distress associated with symptoms/problems ${ }^{32,41}$ compared with those in the control group, irrespective of cancer type or stage.

Quality of life. Survivors of breast cancer, ${ }^{22}$ patients with nonlocalized breast cancer or colorectal cancer, ${ }^{23}$ and groups of patients with mixed cancer diagnoses at an advanced stage $e^{21,31,42}$ or at various clinical stages ${ }^{24,28}$ had no significant postintervention effects in nine CTs (Table 2; Appendix Table A3). In terms of overall QoL, ES ranged from 0.04 to 0.59 , but were mainly small in magnitude. Nevertheless, rates of diseased QoL were reduced in women with breast cancer 6 months after surgery in the experimental group compared with the control group $(d=0.35) .{ }^{26}$ Among patients with lung cancer, QoL scores deteriorated in the experimental group more than in the standard-care group over the 16 weeks of observation. ${ }^{29}$ Velikova et $\mathrm{al}^{38}$ reported improvements in patient QoL scores at treatment initiation that were influenced by whether QoL was actually discussed during consultations. ${ }^{38}$

Psychological symptoms. Results were generally unsupportive of significant postintervention effects on anxiety and/or depression regardless of whether direct real-time ${ }^{18,23}$ or indirect ${ }^{20}$ patient feedback was made available to HPs. This was evident despite overall reductions in psychological distress over time. ${ }^{27}$ Similarly, McLachlan et $\mathrm{al}^{28}$ found no overall intervention effects on depression scores, but the subgroup of patients classified as moderately or severely depressed benefitted more from the intervention. Where significant improvements in anxiety or depression were reported, ${ }^{42}$ these were small-tomoderate in magnitude $(d=0.15$ to 0.42$)$ and not universal across all assessment PROMs.

Supportive care needs. Five CTs provided generally unclear evidence; despite some small-to-moderate ES ( $d=0.16$ to 0.58$)$ across domains of need, these were not always in favor of the experimental group (Appendix Table A3). The PROM intervention was no better than usual care in tackling needs of patients in two trials. ${ }^{18,23}$ We found statistically significant between-group differences in 13 of 19 categories of perceived need ${ }^{32}$ and sexual health concerns $(d=0.49)^{22}$ in favor of the experimental group among patients with hematologic malignancies ${ }^{32}$ and breast cancer, ${ }^{22}$ respectively. In a non-RCT, patients receiving routine psychological screening reported more psychological, information, and physical/daily living needs, but not sexuality needs, at 6 months postbaseline compared with the unscreened cohort. ${ }^{36}$

\section{Processes of Care}

Medical decisions made/advice given/changes in treatment/referrals made. Despite being the outcomes most frequently investigated (Table 3), evidence 







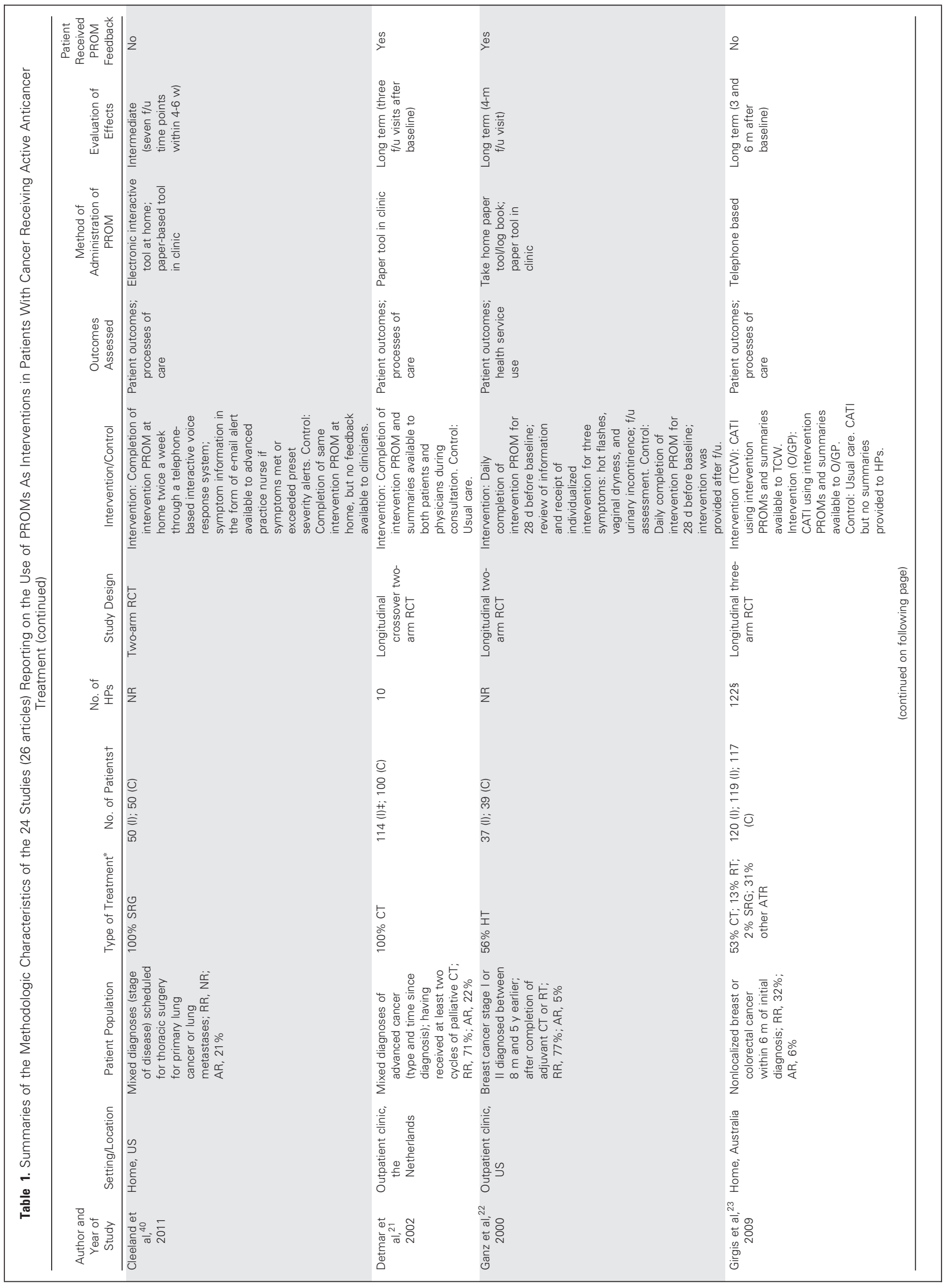




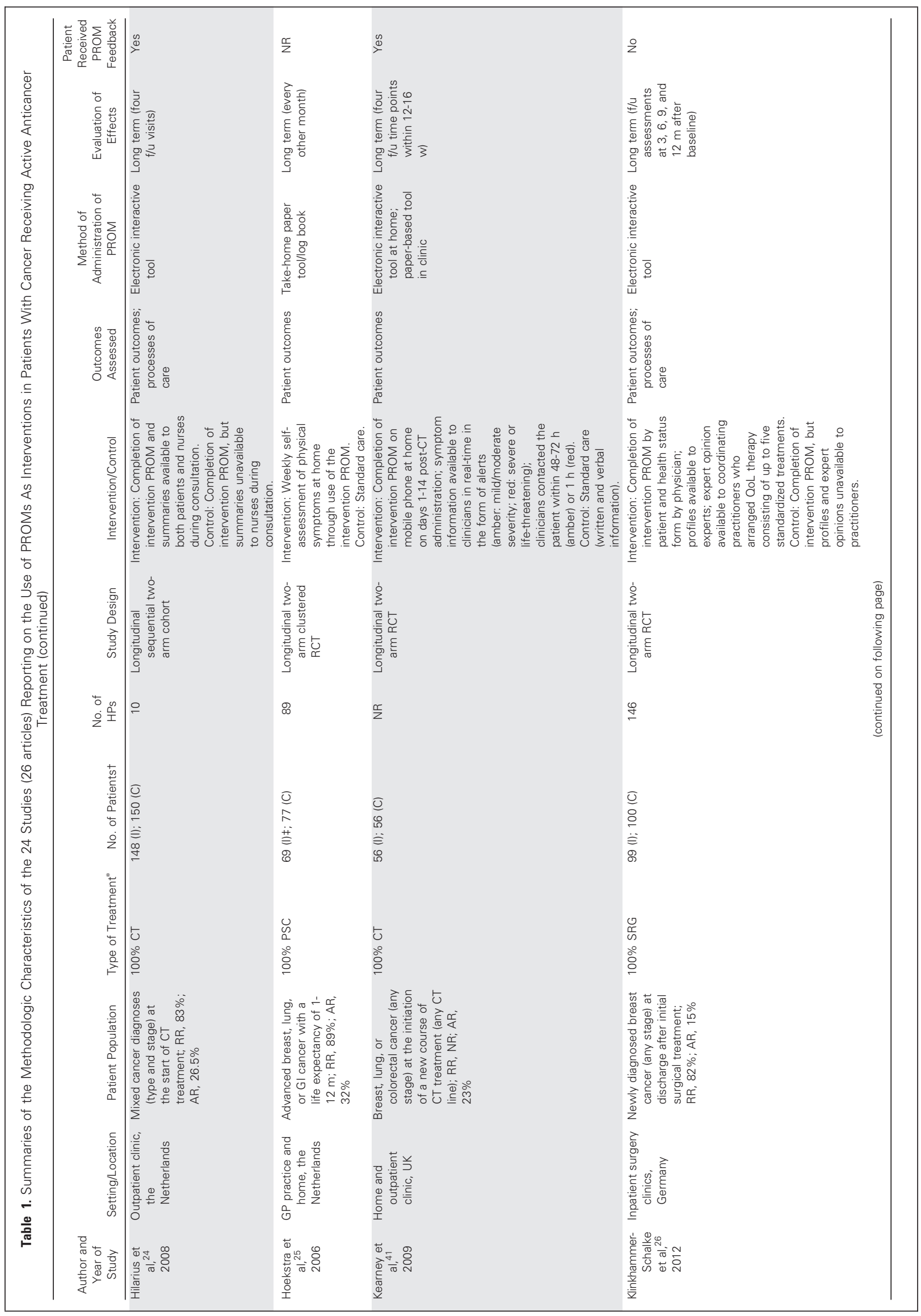




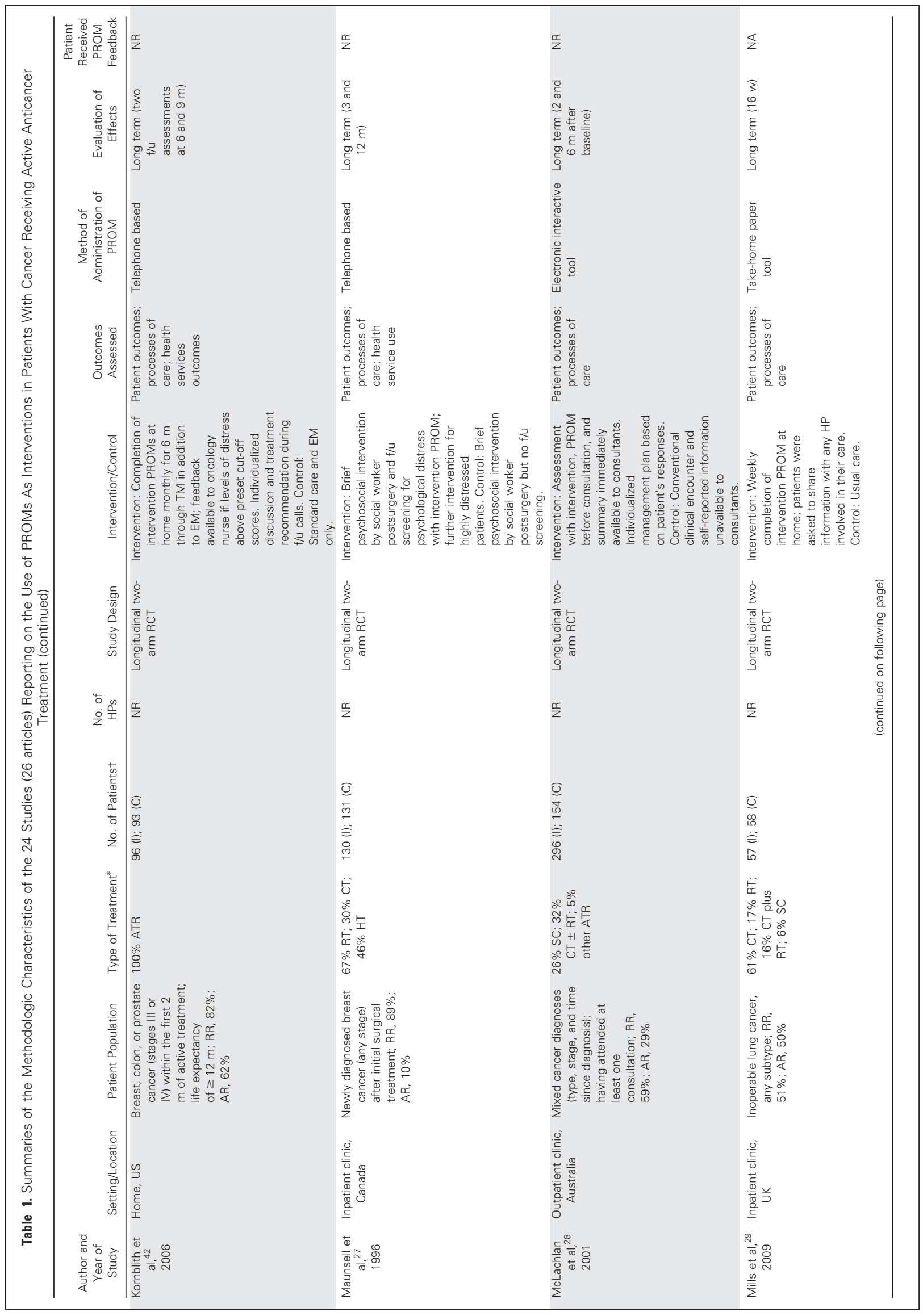




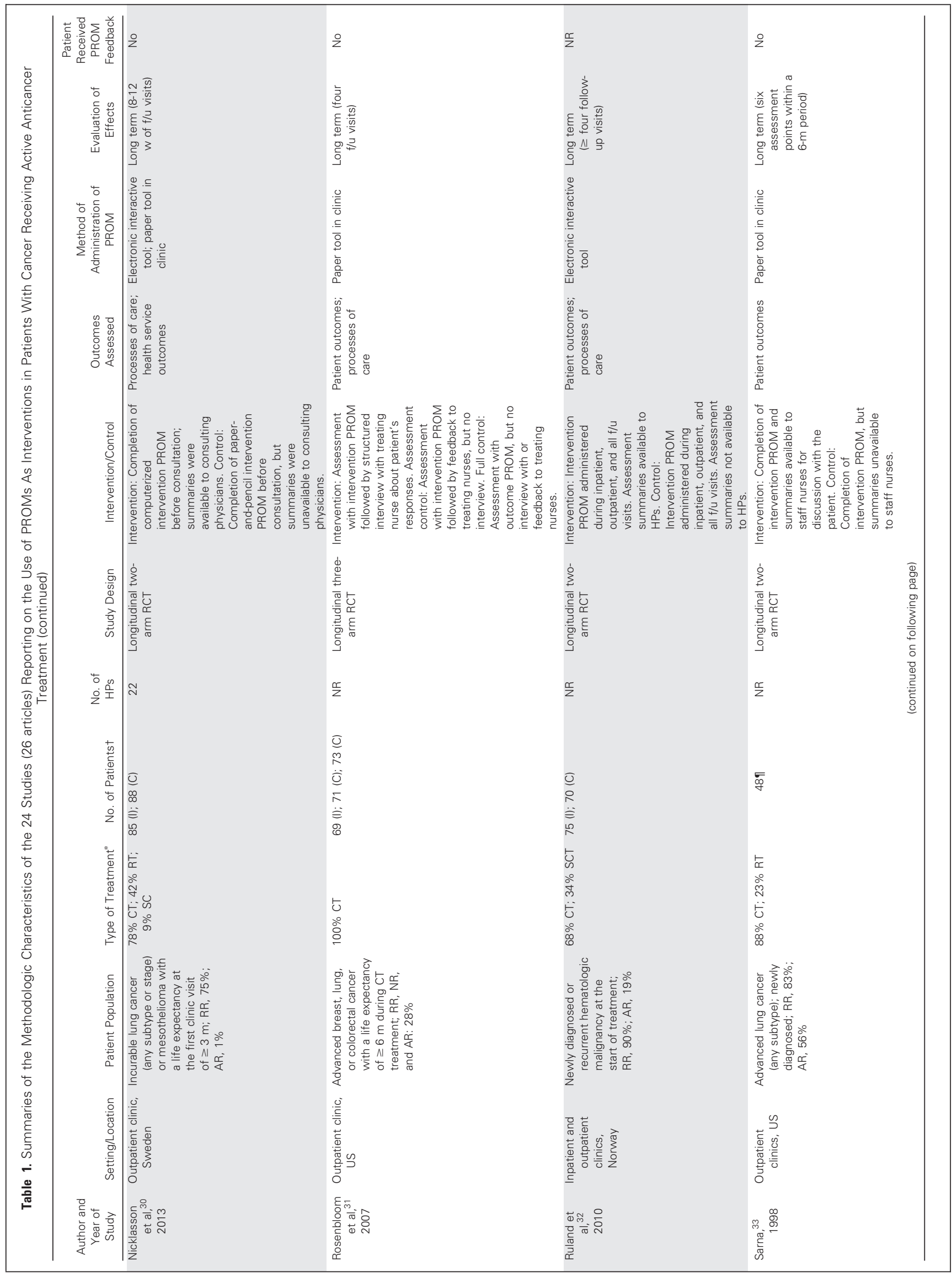




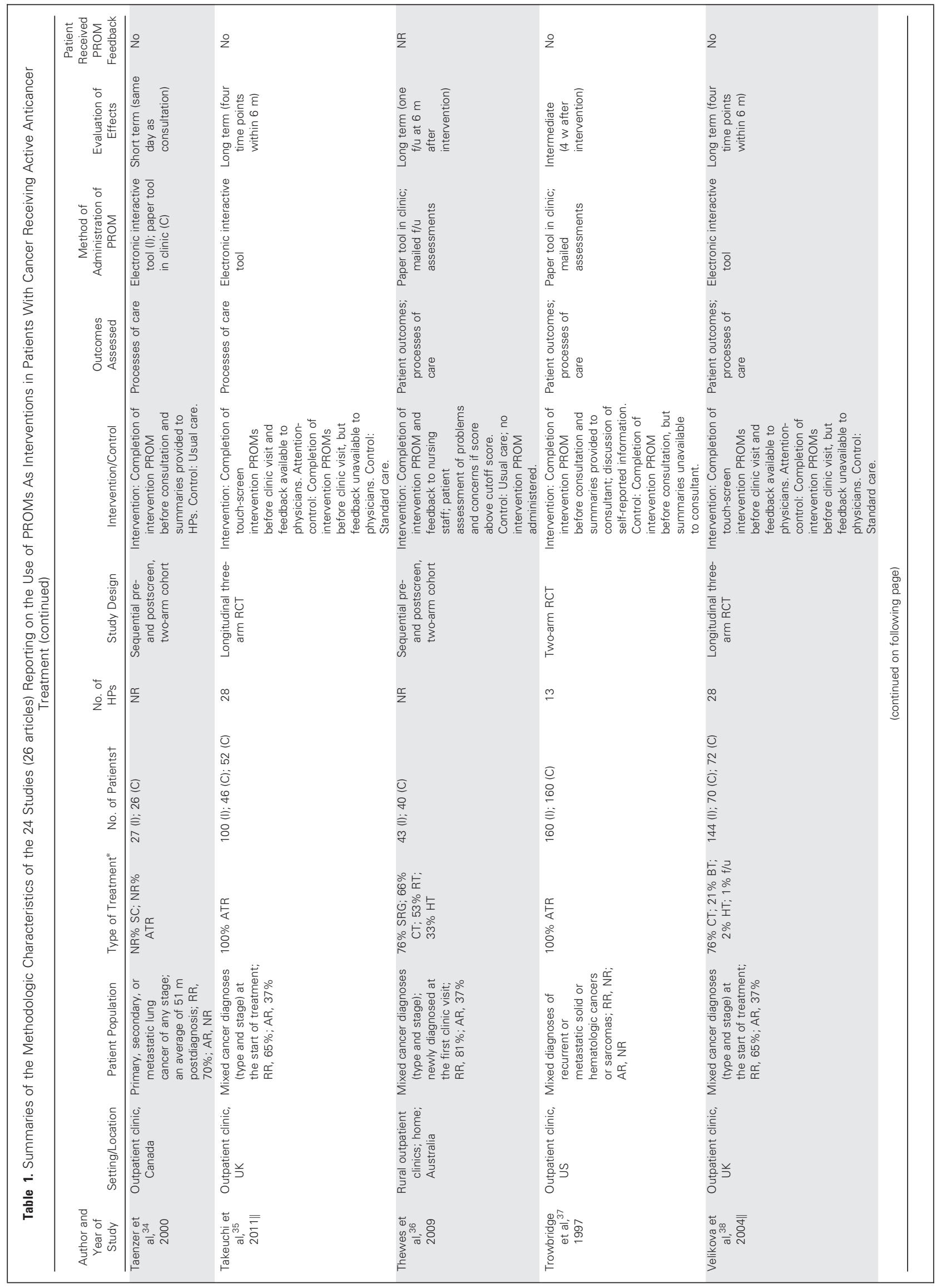




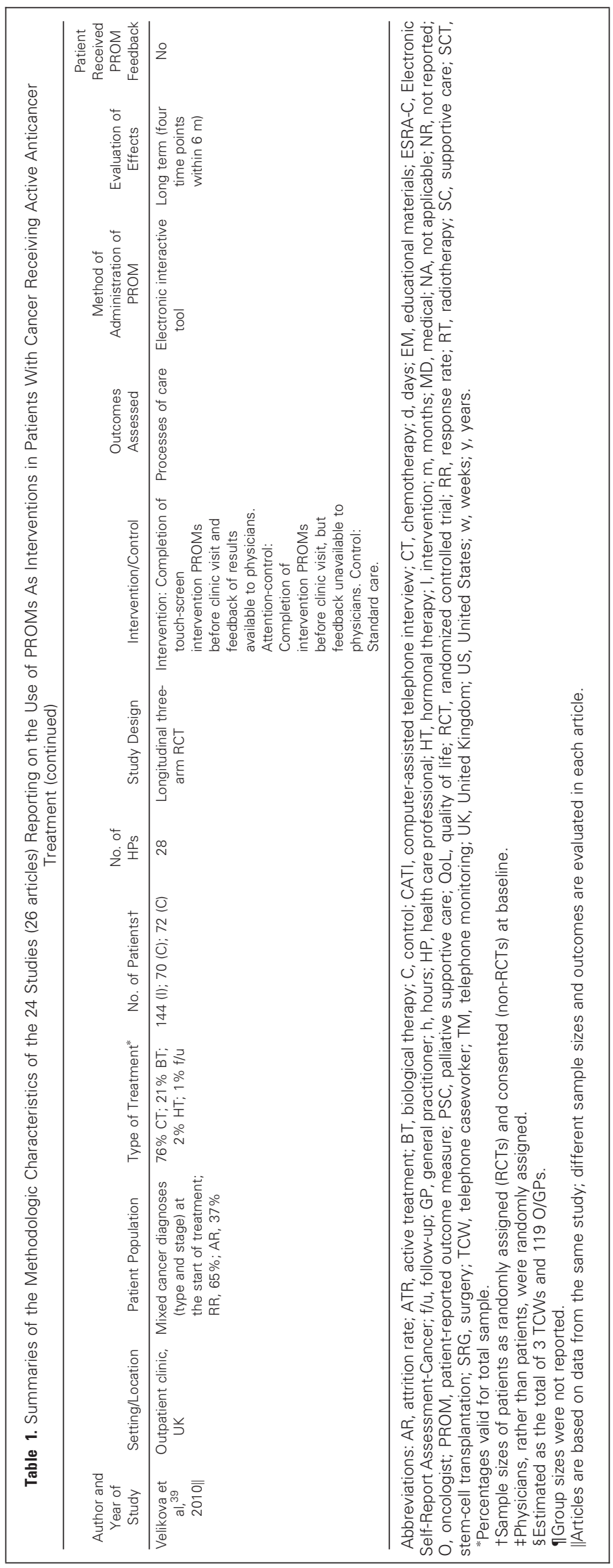




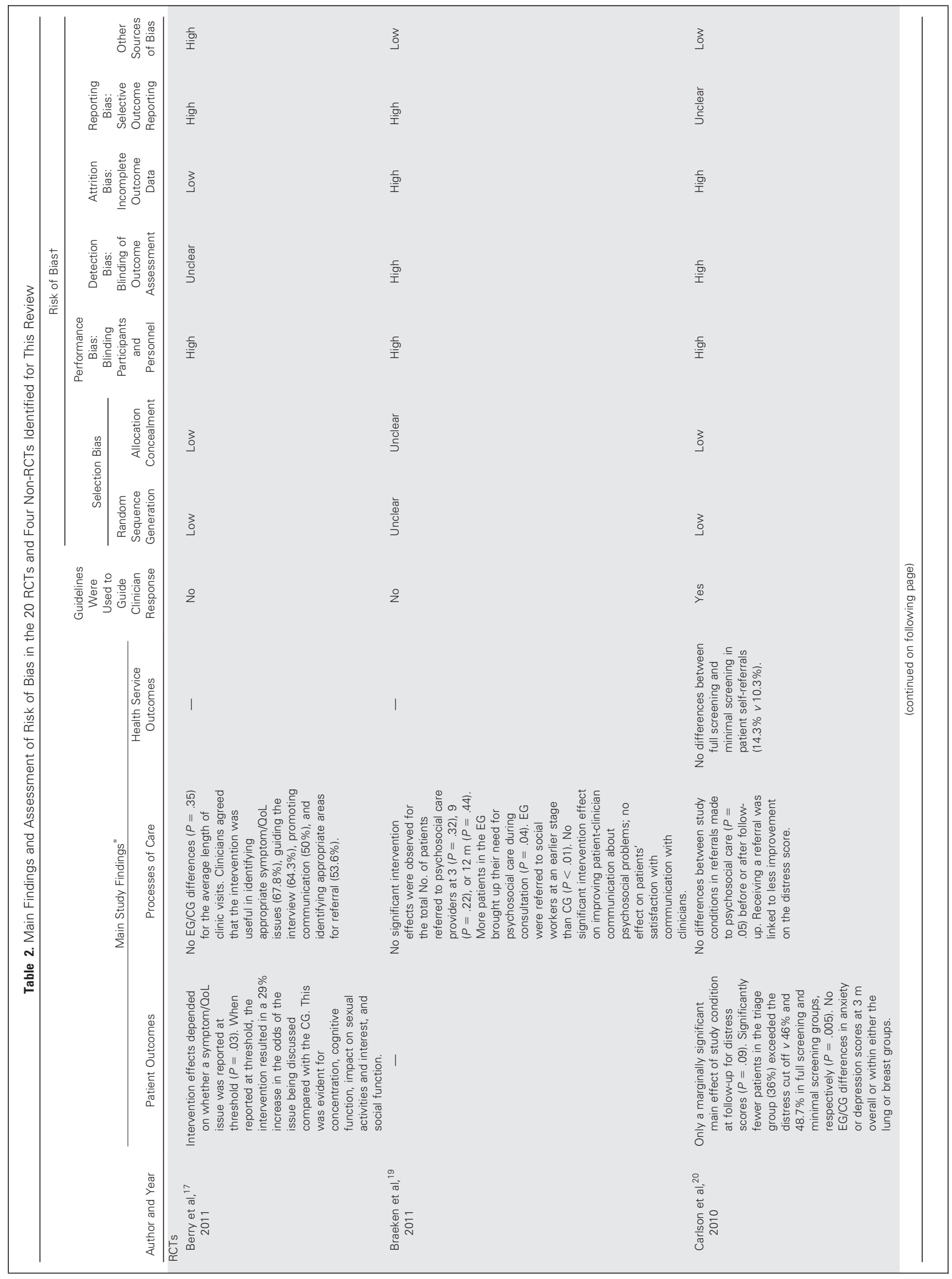




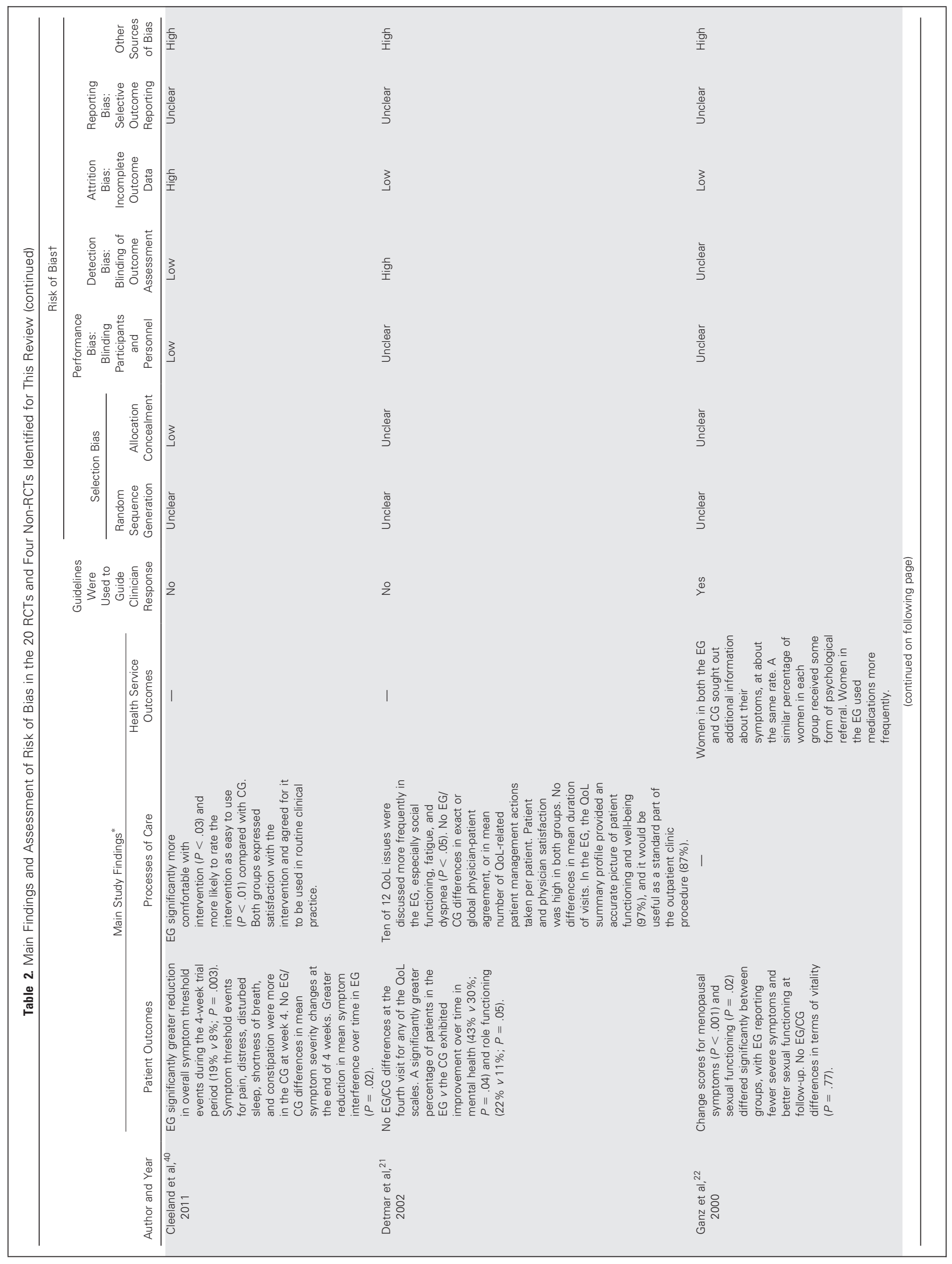




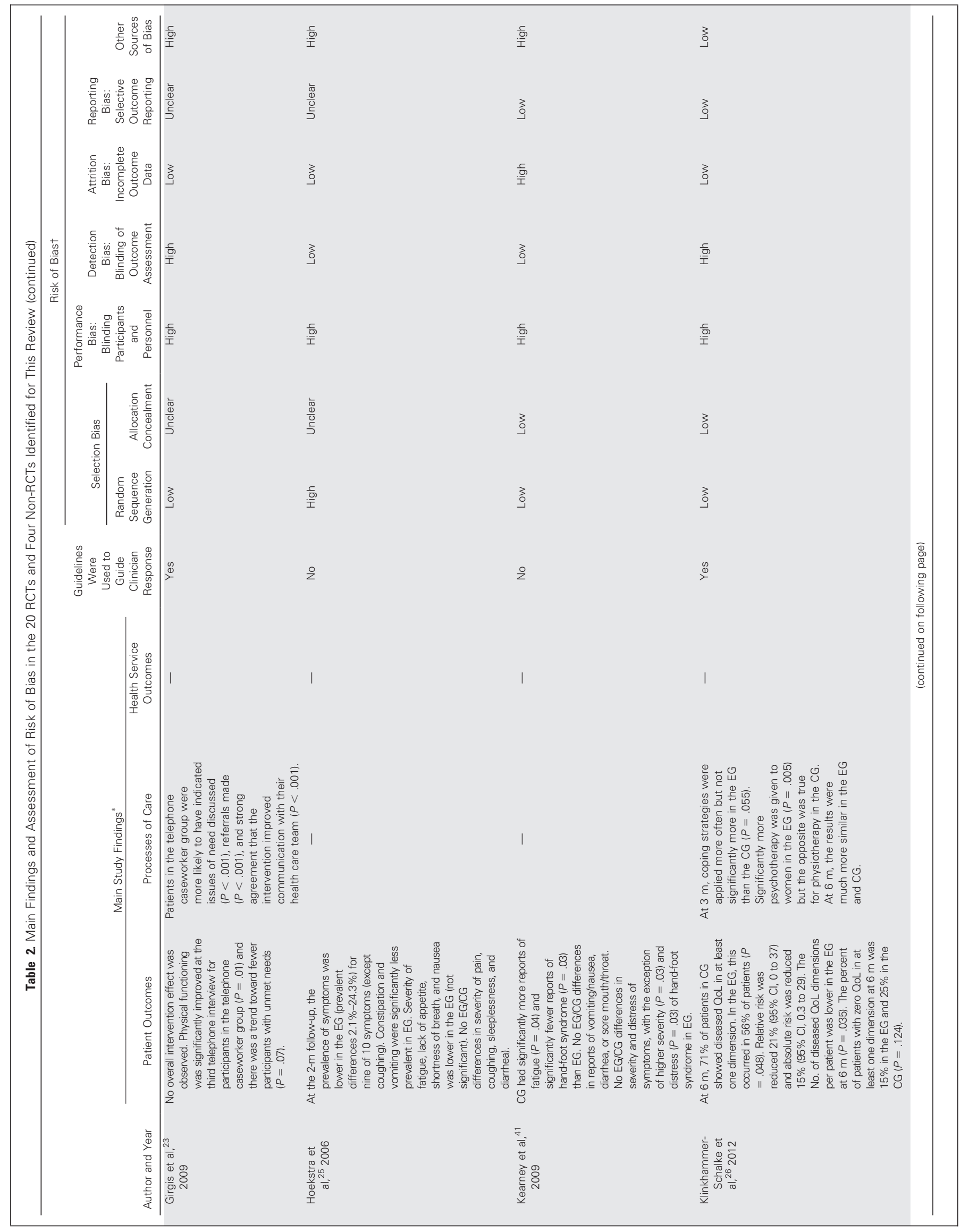




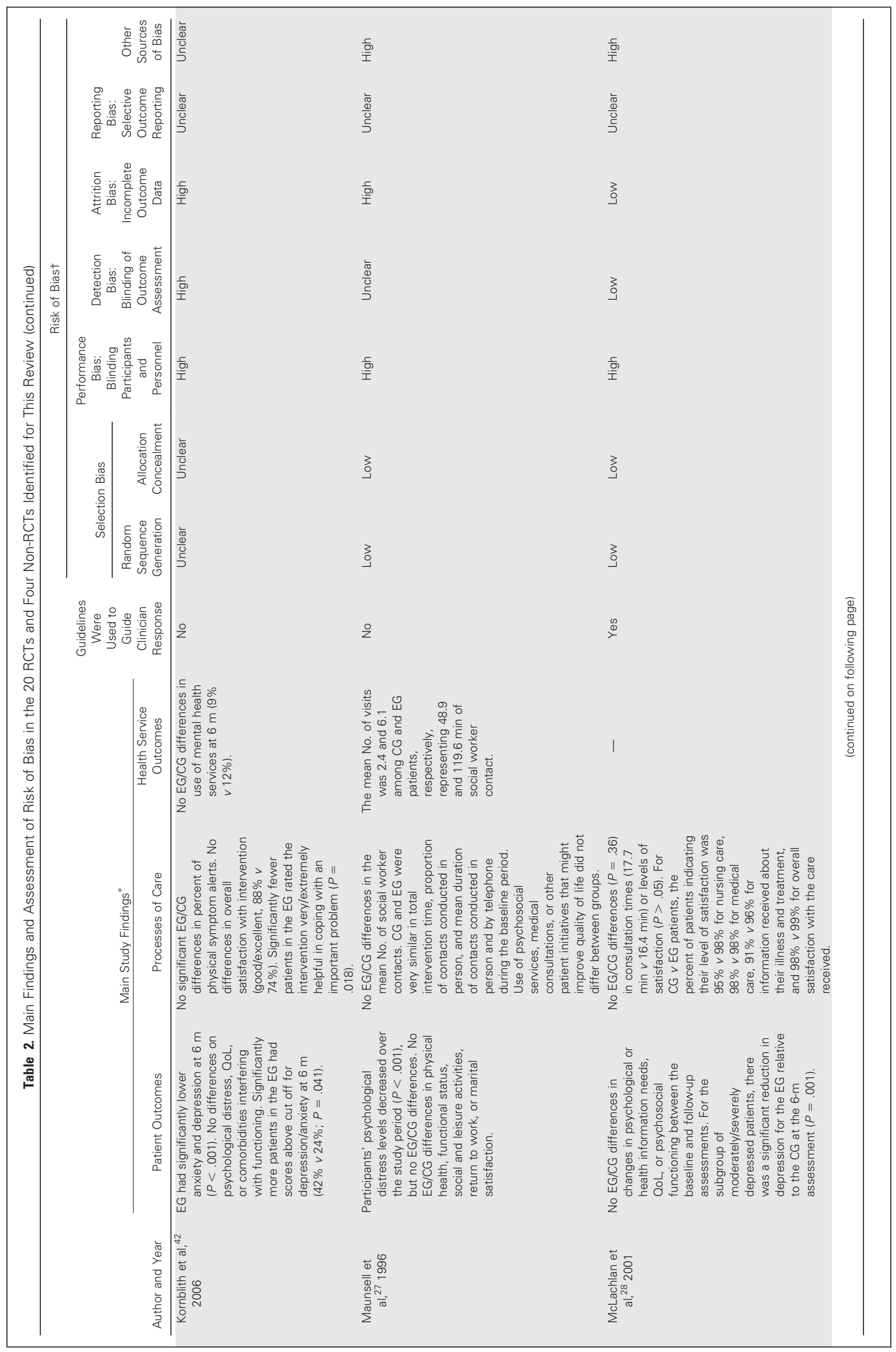




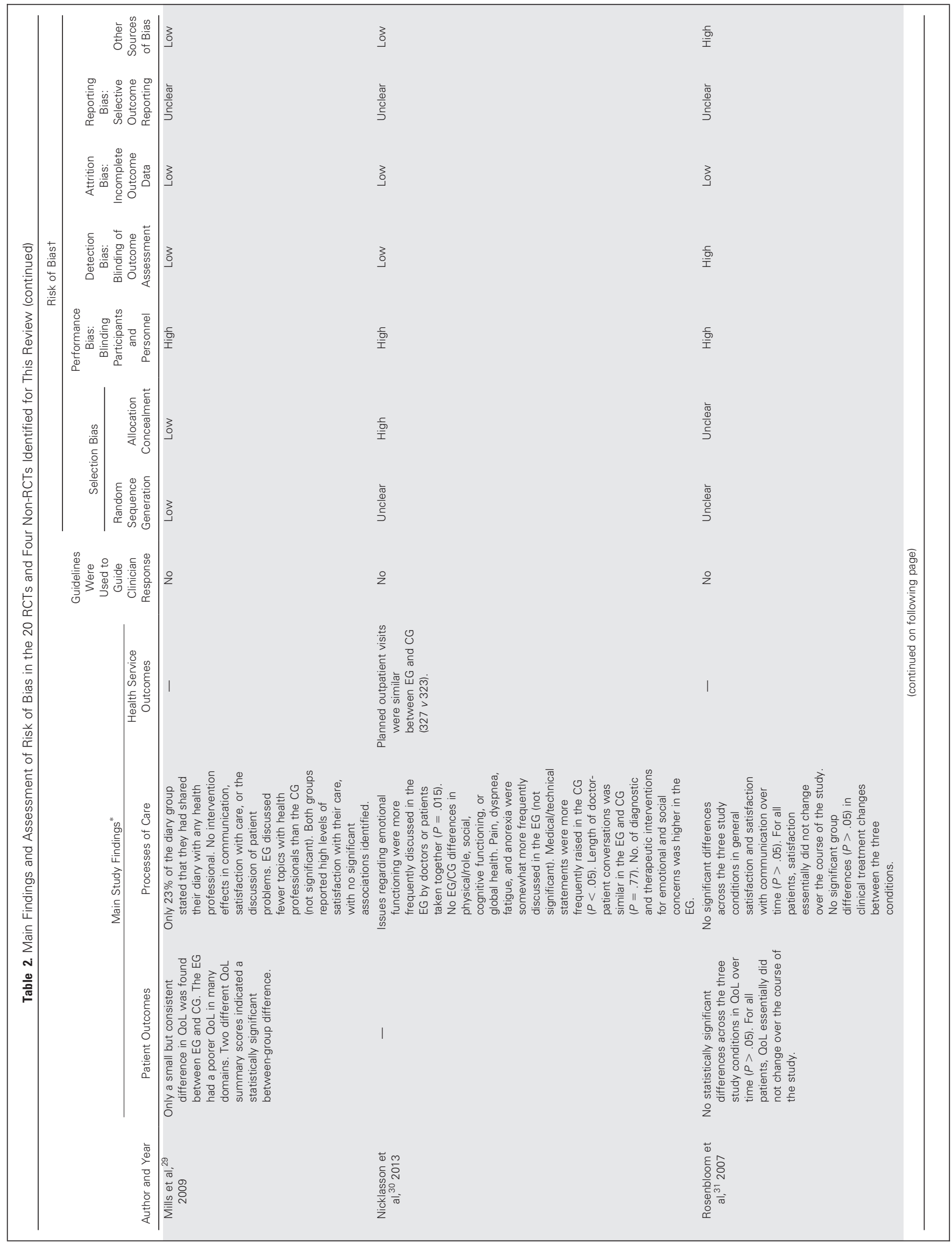




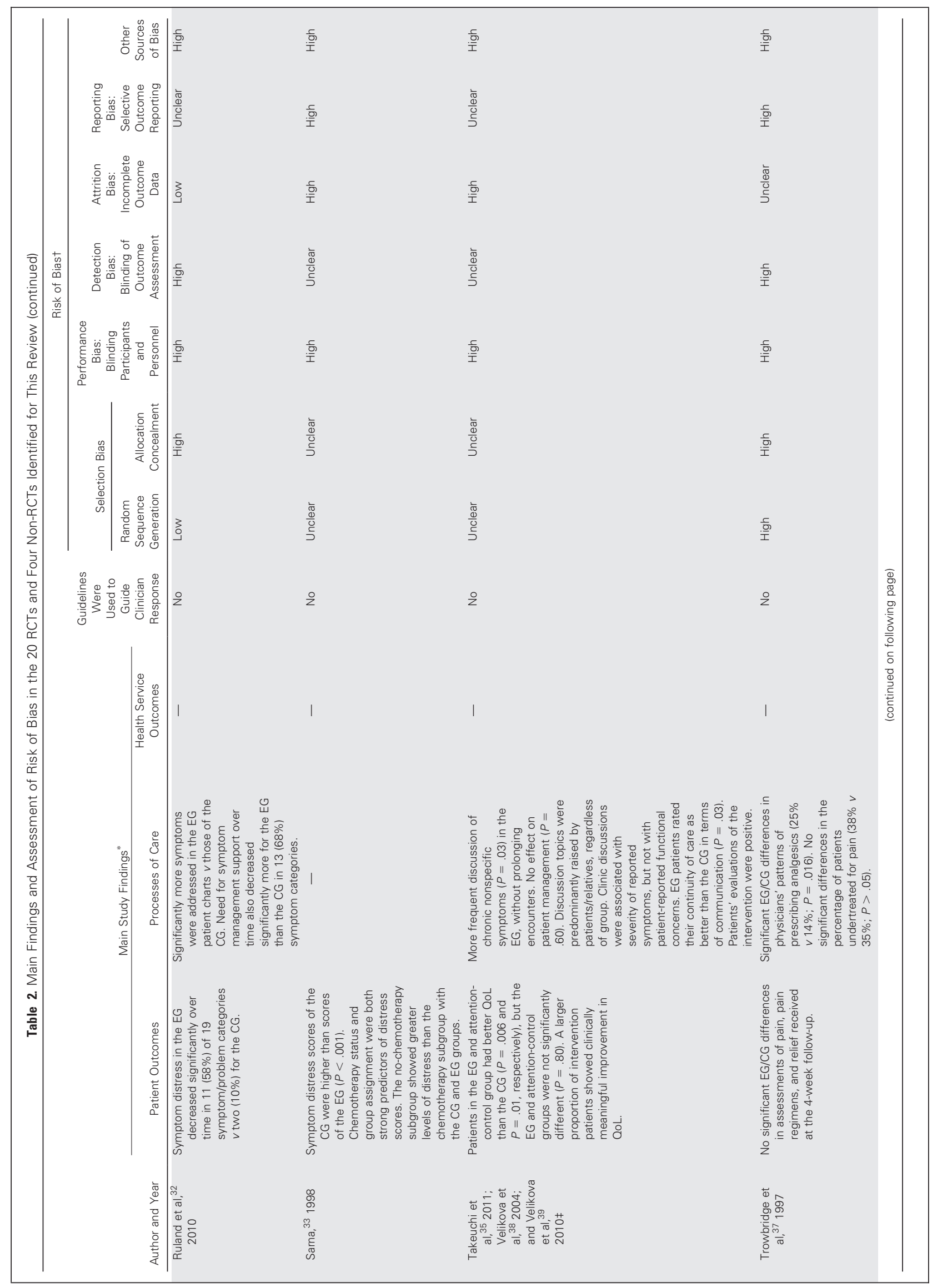




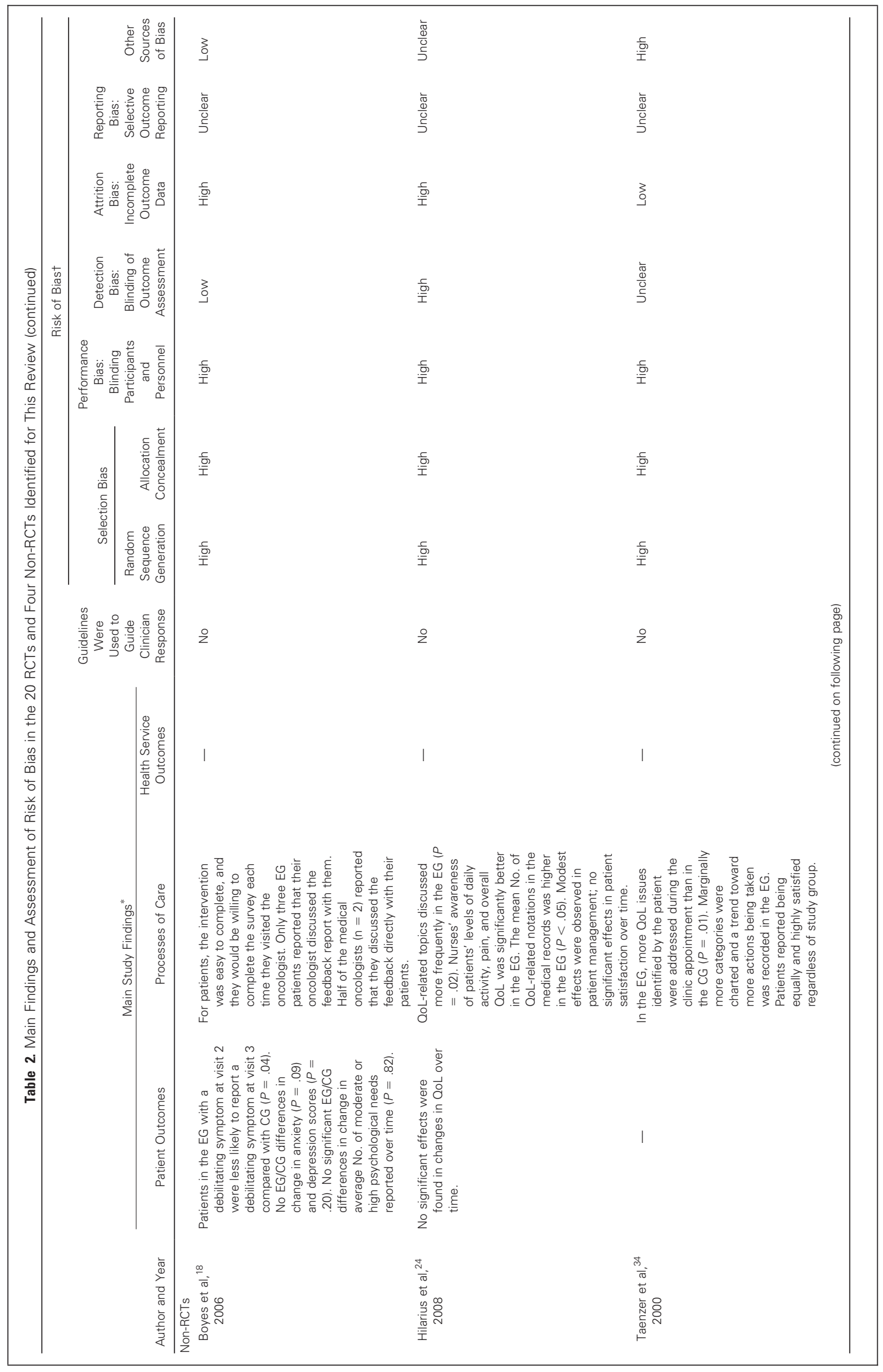




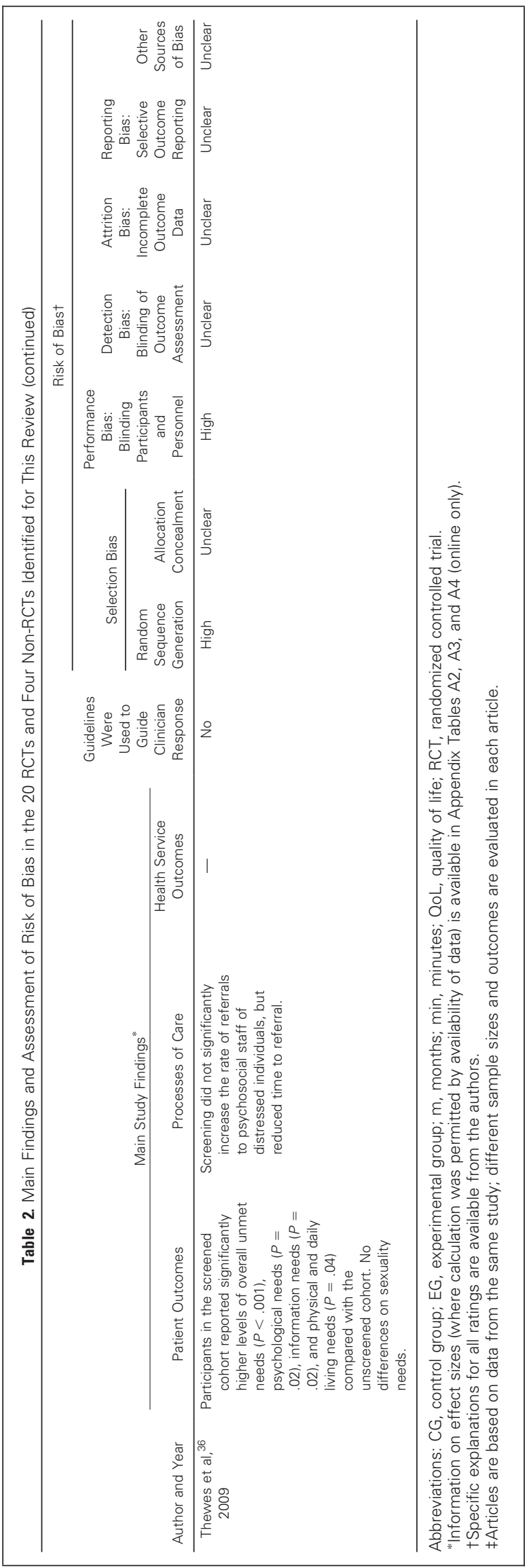


Table 3. Classification of Study Outcomes According to the Three Prespecified Outcome Categories $(n=24)$

\begin{tabular}{|c|c|c|c|c|c|c|c|c|}
\hline \multicolumn{3}{|c|}{ Patient Outcomes } & \multicolumn{3}{|l|}{ Processes of Care } & \multicolumn{3}{|c|}{ Health Service Outcomes } \\
\hline Classification & $\begin{array}{l}\text { No. of } \\
\text { Studies }\end{array}$ & $\%$ & Classification & $\begin{array}{l}\text { No. of } \\
\text { Studies }\end{array}$ & $\%$ & Classification & $\begin{array}{l}\text { No. of } \\
\text { Studies }\end{array}$ & $\%$ \\
\hline $\begin{array}{l}\text { Physical symptoms: } \\
\text { prevalence and/or } \\
\text { severity } \\
18,22,25,32,37,40,41\end{array}$ & 7 & 29.2 & $\begin{array}{l}\text { Patient actual use of the intervention } \\
\text { PROM }^{25,29}\end{array}$ & 2 & 8.3 & $\begin{array}{l}\text { Health services use/ } \\
\text { self-referrals }{ }^{20,22,42}\end{array}$ & 3 & 12.5 \\
\hline QoL $21-24,26,28,29,31,38,42$ & 10 & 41.7 & $\begin{array}{l}\text { Duration of contacts with } \\
\text { HPs }^{17-19,27,28,30,38}\end{array}$ & 7 & 29.2 & Contact with $\mathrm{HPs}^{27,30}$ & 2 & 8.3 \\
\hline $\begin{array}{l}\text { Psychological } \\
\text { symptoms }{ }^{18,20,23,27,28,42}\end{array}$ & 6 & 25 & $\begin{array}{l}\text { Patient engagement in self-care } \\
\text { actions } \text { s }^{27}\end{array}$ & 1 & 4.2 & & & \\
\hline $\begin{array}{l}\text { Supportive care } \\
\text { needs }^{18,22,23,32,36}\end{array}$ & 5 & 20.8 & $\begin{array}{l}\text { Patient outcomes discussed during } \\
\text { consultation } 17,19,21,24,29,30,34,35,38\end{array}$ & 8 & 33.3 & & & \\
\hline Overall distress ${ }^{20,31,33}$ & 3 & 12.5 & $\begin{array}{l}\text { HP acceptability/evaluation of } \\
\text { intervention }{ }^{7-19,21,24,38,39}\end{array}$ & 6 & 25.0 & & & \\
\hline Overall physical health ${ }^{27,42}$ & 2 & 8.3 & $\begin{array}{l}\text { Patient satisfaction with } \\
\text { care/communication with treating } \\
\text { team }^{19,21,23,24,28,29,31,34,37,39,40}\end{array}$ & 11 & 45.8 & & & \\
\hline Working hours ${ }^{27}$ & 1 & 4.2 & $\begin{array}{l}\text { Patient outcomes addressed in } \\
\text { patient records } \\
32,34\end{array}$ & 2 & 8.3 & & & \\
\hline Social support ${ }^{27}$ & 1 & 4.2 & $\begin{array}{l}\text { Medical decisions made/advice } \\
\text { given/changes in } \\
\text { treatment/referrals made }{ }^{19-} \\
21,23,24,26,30,31,34,36,37\end{array}$ & 11 & 45.8 & & & \\
\hline Social activity ${ }^{27}$ & 1 & 4.2 & HP use of PROM information 38,39 & 1 & 4.2 & & & \\
\hline Physical activity 27 & 1 & 4.2 & $\begin{array}{l}\text { HP satisfaction with encounter with } \\
\text { the patient }{ }^{21}\end{array}$ & 1 & 4.2 & & & \\
\hline \multirow[t]{5}{*}{ Marital satisfaction ${ }^{27}$} & 1 & 4.2 & $\begin{array}{l}\text { HP awareness of patient } \\
\text { outcomes }^{21,24}\end{array}$ & 2 & 8.3 & & & \\
\hline & & & $\begin{array}{l}\text { Patient satisfaction with } \\
\text { intervention } \\
19,21,24,36,39,40,42\end{array}$ & 7 & 29.2 & & & \\
\hline & & & $\begin{array}{l}\text { Impact of referrals on patient } \\
\text { outcomes }\end{array}$ & 1 & 4.2 & & & \\
\hline & & & $\begin{array}{l}\text { Perceived continuity and } \\
\text { coordination of care }{ }^{39}\end{array}$ & 1 & 4.2 & & & \\
\hline & & & Timing of referrals ${ }^{19,36}$ & 2 & 8.3 & & & \\
\hline
\end{tabular}

Abbreviations: HP, health professional; PROM, patient-reported outcome measure; QoL, quality of life.

of intervention effects on actions taken as a result of PROM feedback becoming available to clinicians remains generally ambiguous (Appendix Table A4). No significant intervention effects were reported in the number of patients referred to psychosocial care ${ }^{19,20,36}$ or in clinical actions taken. ${ }^{21,24,31} \mathrm{Al}-$ though at 3 months after the intervention women with breast cancer in the experimental group were offered counseling and psychotherapy services more often, at 6 months this difference disappeared. ${ }^{26}$ When PROMs were used to increase physician awareness of patients' levels of pain, a significant change $(d=0.41)$ in analgesic prescription patterns was found to favor the experimental group. ${ }^{37}$ During treatment for chest malignancies, significantly more patients in the experimental group received diagnostic and therapeutic services for emotional and social concerns, ${ }^{30}$ but numbers of QoL-related actions taken per patient were similar across study groups. ${ }^{34}$

Patient satisfaction with care and/or communication with team. Regardless of study condition, patient remarks on satisfaction with care and/or communication with HPs were generally positive. ${ }^{19,21,24,28,29,31,34,39,40}$ Though eight $\mathrm{CTs}^{19,24,28,29,31,34,40}$ failed to show significant intervention effects (Appendix Table A4). In the studies in which postintervention gains were reported, the positive effects referred to greater satisfaction with emotional support in the palliative chemotherapy context, ${ }^{21}$ greater satisfaction with patients receiving follow-up from oncology nurses rather than general practitioners (though differences from usual care were not examined), ${ }^{23}$ and enhanced communication with physicians in the outpatient setting compared with standard care. ${ }^{39}$

Patient outcomes discussed during consultation. Regardless of patients' cancer type, significant postintervention increases over time in the frequency of discussions pertinent to patient outcomes during consultations were re- corded. ${ }^{35,38}$ The odds of such outcomes being discussed seemed to depend on whether these were reported at a level indicating a problem. ${ }^{17}$ Though emotional problems tend to be discussed more often during consultations in the experimental group, ${ }^{19}$ social and sexual functioning issues may be those on which the intervention proves most effective. ${ }^{17}$ Still, the overall patientphysician communication may not significantly improve. ${ }^{19}$ In the lung cancer population, significantly more symptoms were discussed and addressed during consultations, ${ }^{34}$ but intervention effects on QoL discussions fell short of significance. Much greater intervention effects were reported in the context of palliative chemotherapy (Appendix Table A4), ${ }^{21}$ regarding overall communication about dyspnea $(d=0.40 \text { to } 0.77)^{21,24}$; social functioning $(d=0.49)$ and fatigue $(d=0.38)^{21}$; and sleep problems $(d=0.66)$, constipation $(d=0.40)$, diarrhea $(d=0.67)$, and cognitive functioning $(d=0.66) .{ }^{24}$

HP acceptability/evaluation of intervention. Where addressed, intervention acceptability was moderate to high across all CTs (Table 2), with rates of perceived usefulness ranging from less than $50 \%$ to $68 \%$. HPs felt obtaining an overall assessment of the patient was more helpful ${ }^{21,38,39}$ to identify issues of concern ${ }^{17,19,21,38}$ and to guide discussions with patients ${ }^{17-19,24}$ rather than in communicating with patients ${ }^{17,19}$ and in managing and enhancing the care provided. ${ }^{18,38}$ Yet, in two similar CTs, all physicians ${ }^{21}$ and nurses ${ }^{24}$ agreed that the intervention facilitated patient-clinician communication. The ability of HPs to identify psychosocial concerns ${ }^{19,21}$ and address difficult subjects such as sexuality issues ${ }^{24}$ was also enhanced. Although actual changes in HP communication styles may not be seen even following the intervention, ${ }^{19}$ physicians $^{21,39}$ and nurses ${ }^{24}$ seem willing to continue using the PROM summary in everyday practice. Nurses significantly more frequently found PROM 
interventions beneficial ${ }^{17}$ and felt that use of relevant information resulted in more efficient use of their time. ${ }^{24}$

Patient satisfaction with intervention. Overall satisfaction with intervention was evident for at least $80 \%$ of patients. ${ }^{40,42}$ The PROM interventions were seen as easy to use ${ }^{40}$ and a useful way for patients to describe their situation ${ }^{39}$ and communicate important information to HPs. ${ }^{19}$ Patients expressed their willingness to continue using it in routine care. ${ }^{39,40}$ However, in the Kornblith et $\mathrm{al}^{42} \mathrm{CT}$, percentages of patients rating the PROM intervention as very or extremely helpful in coping with an important problem were notably low and favored the control rather than the experimental group (37\% v 14\%; $d=0.69$ ). More than $83 \%$ of patients regarded the PROM content important for them and its use necessary for all patients receiving treatment. ${ }^{19,36}$ Moreover, almost all patients (93\%) appreciated having been asked about their emotional well-being during treatment. ${ }^{36}$ In the palliative care setting, patients agreed that the summary profile enhanced their physician's or nurse's awareness of their health problems ( $79 \%$ to $89 \%$ ), and that it would be useful as a standard part of their consultations ( $87 \%$ to $99 \%))^{21,24}$

HP awareness of patient outcomes. In the context of palliative chemotherapy, no intervention effects were reported on the magnitude of patientphysician agreement about patients' physical, emotional, and social well-being and daily activities $\left(d=0.09\right.$ to 0.50 ; Appendix Table A4). ${ }^{21}$ The only exception was greater agreement in ratings of social functioning in the experimental group, but this applied only to the subgroup of patients who reported moderate-to-severe problems. ${ }^{21}$ Oncology nurses' awareness of daily activities, pain, and QoL was significantly higher in the experimental group during the fourth patient visit. ${ }^{24}$ Positive intervention effects were reported in patient care documentation in the medical records of patients being treated for hematologic malignancies ${ }^{32}$ and in the number of QoL issues charted in records of patients with lung cancer. ${ }^{34}$

Timing of referrals. One RCT revealed that PROM feedback resulted in significantly earlier postconsultation referral of patients in the experimental versus the control group by an average of three weeks. ${ }^{19}$ In a sequential cohort trial of patient-distress screening, average time to referral in the unscreened cohort was 14 days compared with a considerably earlier referral of only 5 days in the screened cohort. ${ }^{36}$

\section{Health Services Outcomes}

Only five CTs explored the effects of the routine use of PROMs on HSOs (Table 3; Appendix Table A5), namely, numbers of patients making use of health services ${ }^{20,22,42}$ and frequency of contacts with health professionals. ${ }^{27,30}$ Ganz et $\mathrm{al}^{22}$ reported only minimal use of services after referral to psychosocial care in women with breast cancer; whereas prevalence of cases in which patients sought professional help was similar irrespective of study group among newly diagnosed patients with lung cancer and breast cancer. ${ }^{20}$ Among patients with advanced breast, colorectal, or prostate cancer, use of mental health services at 6 months after intervention was equally minimal regardless of study condition $(P=.34){ }^{42}$ In terms of frequency of patient-HP contacts, positive intervention effects were found among women with breast cancer ${ }^{27}$ but not among patients with chest malignancies. ${ }^{30}$

\section{DISCUSSION}

We found only tentative evidence regarding the effectiveness of PROM interventions to improve the quality of care provided to patients receiving active anticancer treatments. We used strict systematic methods during identification ${ }^{12}$ and risk-of-bias appraisal ${ }^{13}$ of all trials included here. We included $24 \mathrm{CTs}$, which investigated a wide range of outcomes, thus producing a disparate set of data and indicating lack of consensus around the role of PROMs and the range of outcome measures in clinical practice. Evidence suggests that, irrespective of the context of chronic illness, the impact of PROMs on POs is weak. ${ }^{9,44}$ Where possible, we calculated ES in an attempt to quantify the magnitude of these effects, and our findings indicate inconsistencies in the overall significance (statistical or clinical) and low-to- moderate intervention effectiveness. Importantly, efficacy of the CTs reviewed seems low, confirming findings from previous reviews. ${ }^{5,9,44}$

Contrary to the limited evaluation of HSOs, PoCs were the most frequently investigated outcomes in our sample of trials. Mixed findings emerged regarding medical decisions made or actions taken by HPs as a result of the availability of PROM data. Changes in HP practices fell short of significance and, where such changes were documented, ${ }^{30,37}$ the associated ES were still small. It is unclear whether limited referral options, additional subjective HP assessments, or other health care-related factors influenced the use of PROMs in practice. Patient satisfaction with care did not improve significantly, possibly owing to the presence of ceiling effects. Moreover, achievable improvements in patient communication with HPs, especially regarding emotional health issues, were documented, but ES were quite small. Somewhat greater ES can be proposed with regard to the actual discussion of POs during consultations, particularly physical symptoms, but not necessarily around supportive care needs. ${ }^{19}$

Fewer than $30 \%$ of the CTs addressed the important question of whether the use of PROM interventions appeals to patients and HPs. Though HPs may view PROMs as useful toward a more comprehensive or systematic assessment, communication is not always enhanced. In addition, there is still limited (albeit positive) evidence about whether HPs wish PROMs to become routine practice. Whether patients can comply with the systematic use of PROMs during treatment and encounters with the clinical team is equally unclear. Despite limited evidence, including electronic systems to enhance data collection and management, as well as use of clinical algorithms to support clinicians in the management of identified areas for intervention, might potentially increase adherence to and acceptability of PROMenhanced clinical assessments.

Current data also suggest that patient physical symptoms and distress may be more amenable to improvement after PROM interventions than QoL, supportive care needs, or psychological symptoms. Even with the exception of the few studies that examined the use of health services by patients or contacts with HPs, important aspects of an intervention's applicability, such as patient safety or costeffectiveness and cost-efficiency, are yet to be included as potential end points to encourage policy makers to consider making changes in the way cancer care is provided. Despite this lack of evidence, the Department of Health in England is aiming to extend the use of PROMs in a wider range of conditions in that country's National Health Service, ${ }^{45}$ which would include cancer care.

Finally, measurement bias interfering with the effects of PROM interventions documented in this review should also be considered. Arguably, not all tools used in the delivery of interventions were originally developed as PROMs, which might have affected the reliability of reported outcomes and their subsequent interpretation. In addition, the psychometric robustness of the PROMs used to deliver and/or evaluate intervention effects is questionable and might have interfered with its ability to capture the actual magnitude of such effects. Similar comments can be made regarding sources of bias, such as absence of randomization or uncertainty about whether clinicians did use information generated by PROMs during consultations, which may have further affected the trials' internal and external validity and adversely affected credibility of available evidence.

Our search strategy was purposefully inclusive, with an aim to include all relevant literature. However, it was limited to the most common bibliographic databases, as well as to peer-reviewed articles 
and reports published in the English language only. In addition, the gray literature was not searched. Owing to the vast heterogeneity in the studies included, a meta-analytic synthesis was not feasible. Unavailability of data also prevented us from calculating ES for some of the included studies. However, such cases were equally distributed across statistically significant and nonsignificant findings or across the different outcome categories; hence, we are confident that the associated reporting bias has not greatly affected our conclusions.

More research is necessary on the effects of PROM interventions on health outcomes across different types of cancers and treatment modalities. The use of PROMs in clinical practice seems to be most effective in increasing patient satisfaction with communication about emotional concerns. Discussion of POs during consultations may increase and, in some studies, is associated with improved symptom control, increased supportive care measures, and patient satisfaction. Additional patient-related outcomes could be usefully addressed in future trials, including perceived self-care self-efficacy, social activity, work limitations, or survival. Patients and HPs are willing to engage in the routine use of PROMs during anticancer treatment. However, it is paramount that PROM intervention implementation is effective and incorporates strategies that increase patient adherence to the actual use of PROMs and HP engagement in the active incorporation of PROM feedback during encounters with patients. ${ }^{44}$ Consensus is also required on the standardization of PROMs to be used in future trials. Finally, dedicated research is required to support the cost-effective use of PROMs in clinical practice regarding patient safety, clinician burden, and health-services usage. This is an important area of consideration, particularly in times of increasing demands on health care.
AUTHORS' DISCLOSURES OF POTENTIAL CONFLICTS OF INTEREST

Although all authors completed the disclosure declaration, the following author(s) and/or an author's immediate family member(s) indicated a financial or other interest that is relevant to the subject matter under consideration in this article. Certain relationships marked with a " $U$ " are those for which no compensation was received; those relationships marked with a "C" were compensated. For a detailed description of the disclosure categories, or for more information about ASCO's conflict of interest policy, please refer to the Author Disclosure Declaration and the Disclosures of Potential Conflicts of Interest section in Information for Contributors. Employment or Leadership Position: None Consultant or Advisory Role: None Stock Ownership: None Honoraria: None Research Funding: Nora Kearney, Philips HealthCare Expert Testimony: None Patents, Royalties, and Licenses: None Other Remuneration: None

\section{AUTHOR CONTRIBUTIONS}

\section{Conception and design: Grigorios Kotronoulas, Nora Kearney,}

Roma Maguire

Collection and assembly of data: Grigorios Kotronoulas, Roma

Maguire, Alison Harrow, David Di Domenico, Suzanne Croy,

Stephen MacGillivray

Data analysis and interpretation: All authors

Manuscript writing: All authors

Final approval of manuscript: All authors

\section{REFERENCES}

1. Siegel R, DeSantis $C$, Virgo $K$, et al: Cancer treatment and survivorship statistics, 2012. CA Cancer J Clin 62:220-241, 2012

2. Cheng KK, Yeung RM: Impact of mood disturbance, sleep disturbance, fatigue and pain among patients receiving cancer therapy. Eur J Cancer Care (Engl) 22:70-78, 2013

3. Cleeland CS: Symptom burden: Multiple symptoms and their impact as patient-reported outcomes. J Natl Cancer Inst Monogr 16-21, 2007

4. Trotti A, Colevas AD, Setser A, et al: Patientreported outcomes and the evolution of adverse event reporting in oncology. J Clin Oncol 25:5121 5127, 2007

5. Valderas JM, Alonso J: Patient reported outcome measures: A model-based classification system for research and clinical practice. Qual Life Res 17:1125-1135, 2008

6. Espallargues M, Valderas JM, Alonso J: Provision of feedback on perceived health status to health care professionals: A systematic review of its impact. Med Care 38:175-186, 2000

7. Gilbody SM, House AO, Sheldon T: Routine administration of Health Related Quality of Life (HRQoL) and needs assessment instruments to improve psychological outcome: A systematic review. Psychol Med 32:1345-1356, 2002

8. Greenhalgh J, Meadows K: The effectiveness of the use of patient-based measures of health in routine practice in improving the process and outcomes of patient care: A literature review. J Eval Clin Pract 5:401-416, 1999
9. Luckett $T$, Butow PN, King MT: Improving patient outcomes through the routine use of patientreported data in cancer clinics: Future directions. Psychooncology 18:1129-1138, 2009

10. Marshall S, Haywood K, Fitzpatrick R: Impact of patient-reported outcome measures on routine practice: A structured review. J Eval Clin Pract 12:559-568, 2006

11. Mitchell AJ, Waller A, Carlson LE: Implementing a screening programme for distress in cancer settings: Science and practice. Psicooncologia 9:259-275, 2012

12. Moher D, Liberati A, Tetzlaff J, et al: Preferred reporting items for systematic reviews and metaanalyses: The PRISMA statement. Ann Intern Med 151:264-269, W64, 2009

13. Higgins JP, Altman DG, Gotzsche PC, et al: The Cochrane Collaboration's tool for assessing risk of bias in randomised trials. BMJ 343:d5928, 2011

14. Lipsey MW, Wilson D: Practical MetaAnalysis (ed 1). Thousand Oaks, CA, Sage Publications, 2000

15. Wilson BD: Practical Meta-Analysis Effect Size Calculator. http://www.campbellcollaboration.org/escalc/ html/EffectSizeCalculator-SMD-main.php

16. Cohen J: Statistical power analysis for the behavioral sciences (ed 2). Hillsdale, NJ, Lawrence Earlbaum Associates, 1988

17. Berry DL, Blumenstein BA, Halpenny B, et al: Enhancing patient-provider communication with the electronic self-report assessment for cancer: A randomized trial. J Clin Oncol 29:1029-1035, 2011

18. Boyes A, Newell S, Girgis A, et al: Does routine assessment and real-time feedback improve cancer patients' psychosocial well-being? Eur J Cancer Care (Engl) 15:163-171, 2006
19. Braeken AP, Kempen GI, Eekers D, et al: The usefulness and feasibility of a screening instrument to identify psychosocial problems in patients receiving curative radiotherapy: A process evaluation. BMC Cancer 11:479, 2011

20. Carlson LE, Groff SL, Maciejewski O, et al: Screening for distress in lung and breast cancer outpatients: A randomized controlled trial. J Clin Oncol 28:4884-4891, 2010

21. Detmar SB, Muller MJ, Schornagel JH, et al: Health-related quality-of-life assessments and patientphysician communication: A randomized controlled trial. JAMA 288:3027-3034, 2002

22. Ganz PA, Greendale GA, Petersen $L$, et al: Managing menopausal symptoms in breast cancer survivors: Results of a randomized controlled trial. J Natl Cancer Inst 92:1054-1064, 2000

23. Girgis A, Breen S, Stacey F, et al: Impact of two supportive care interventions on anxiety, depression, quality of life, and unmet needs in patients with nonlocalized breast and colorectal cancers. J Clin Oncol 27:6180-6190, 2009

24. Hilarius DL, Kloeg PH, Gundy CM, et al: Use of health-related quality-of-life assessments in daily clinical oncology nursing practice: A community hospital-based intervention study. Cancer 113:628637, 2008

25. Hoekstra J, de Vos R, van Duijn NP, et al: Using the symptom monitor in a randomized controlled trial: The effect on symptom prevalence and severity. J Pain Symptom Manage 31:22-30, 2006

26. Klinkhammer-Schalke $M$, Koller $M$, Steinger $B$, et al: Direct improvement of quality of life using a tailored quality of life diagnosis and therapy pathway: Randomised trial in 200 women with breast cancer. Br J Cancer 106:826-838, 2012 
27. Maunsell $E$, Brisson J, Deschênes $L$, et al: Randomized trial of a psychologic distress screening program after breast cancer: Effects on quality of life. J Clin Oncol 14:2747-2755, 1996

28. McLachlan SA, Allenby A, Matthews J, et al: Randomized trial of coordinated psychosocial interventions based on patient self-assessments versus standard care to improve the psychosocial functioning of patients with cancer. J Clin Oncol 19:41174125, 2001

29. Mills ME, Murray LJ, Johnston BT, et al: Does a patient-held quality-of-life diary benefit patients with inoperable lung cancer? J Clin Oncol 27:70-77, 2009

30. Nicklasson M, Elfström ML, Olofson J, et al: The impact of individual quality of life assessment on psychosocial attention in patients with chest malignancies: A randomized study. Support Care Cancer 21:87-95, 2013

31. Rosenbloom SK, Victorson DE, Hahn EA, et al: Assessment is not enough: A randomized controlled trial of the effects of HRQL assessment on quality of life and satisfaction in oncology clinical practice. Psychooncology 16:1069-1079, 2007

32. Ruland CM, Holte HH, Røislien J, et al: Effects of a computer-supported interactive tailored patient assessment tool on patient care, symptom distress, and patients' need for symptom management support: A randomized clinical trial. J Am Med Inform Assoc 17:403-410, 2010
33. Sarna L: Effectiveness of structured nursing assessment of symptom distress in advanced lung cancer. Oncol Nurs Forum 25:1041-1048, 1998

34. Taenzer P, Bultz BD, Carlson LE, et al: Impact of computerized quality of life screening on physician behaviour and patient satisfaction in lung cancer outpatients. Psychooncology 9:203-213, 2000

35. Takeuchi EE, Keding A, Awad N, et al: Impact of patient-reported outcomes in oncology: A longitudinal analysis of patient-physician communication. J Clin Oncol 29:2910-2917, 2011

36. Thewes B, Butow P, Stuart-Harris R: Does routine psychological screening of newly diagnosed rural cancer patients lead to better patient outcomes? Results of a pilot study. Aust J Rural Health 17:298-304, 2009

37. Trowbridge R, Dugan W, Jay SJ, et al: Determining the effectiveness of a clinical-practice intervention in improving the control of pain in outpatients with cancer. Acad Med 72:798-800, 1997

38. Velikova G, Booth $L$, Smith $A B$, et al: Measuring quality of life in routine oncology practice improves communication and patient well-being: $A$ randomized controlled trial. J Clin Oncol 22:714-724, 2004

39. Velikova G, Keding A, Harley C, et al: Patients report improvements in continuity of care when quality of life assessments are used routinely in oncology practice: Secondary outcomes of a randomised controlled trial. Eur J Cancer 46:2381-2388, 2010
40. Cleeland CS, Wang XS, Shi Q, et al: Automated symptom alerts reduce postoperative symptom severity after cancer surgery: A randomized controlled clinical trial. J Clin Oncol 29:994-1000, 2011

41. Kearney N, McCann L, Norrie J, et al: Evaluation of a mobile phone-based, advanced symptom management system (ASyMS) in the management of chemotherapy-related toxicity. Support Care Cancer 17:437-444, 2009

42. Kornblith $A B$, Dowell JM, Herndon JE II, et al: Telephone monitoring of distress in patients aged 65 years or older with advanced stage cancer: A cancer and leukemia group B study. Cancer 107: 2706-2714, 2006

43. Moher D, Hopewell S, Schulz KF, et al: CONSORT 2010 explanation and elaboration: Updated guidelines for reporting parallel group randomised trials. J Clin Epidemiol 63:e1-e37, 2010

44. Boyce MB, Browne JP: Does providing feedback on patient-reported outcomes to healthcare professionals result in better outcomes for patients? A systematic review. Qual Life Res 22:2265-2278, 2013

45. Devlin N, Appleby J: Getting the most out of PROMs: Putting health outcomes at the heart of NHS decision-making. London, United Kingdom, The King's Fund, 2010. https://www.kingsfund.org.uk/sites/files/kf/ Getting-the-most-out-of-PROMs-Nancy-Devlin-JohnAppleby-Kings-Fund-March-2010.pdf 


\section{Appendix}

\begin{tabular}{|c|c|}
\hline Electronic Databases & Search Terms Used \\
\hline Medline (1946 to May 2012) & 1. exp controlled clinical trial/ \\
\hline EMBASE (1974 to May 2012) & 2. exp randomized controlled trial/ \\
\hline CINAHL (inception to May 2012) & 3. $1 \mathrm{OR} 2$ \\
\hline PsycINFO (inception to May 2012) & $\begin{array}{l}\text { 4. exp neoplasms/OR cancer*.mp. OR neoplasm*.mp. OR carcinoma*.mp. OR oncol*.mp. OR } \\
\text { malignan*.mp. OR tumor".mp. OR tumour*.mp. OR leukemia*.mp. OR leukaemia*.mp. OR } \\
\text { sarcoma*.mp. OR lymphoma*.mp. OR melanoma*.mp. OR blastoma*.mp. }\end{array}$ \\
\hline PBSC (inception to May 2012) & $\begin{array}{l}\text { 5. } 3 \text { AND } 4 \\
\text { 6. (patient reported outcomes OR patient reported outcome OR patient based outcome OR patient } \\
\text { reported outcome measure\$).mp. } \\
\text { 7. inventory.ti. OR inventory.ab. } \\
\text { 8. instrument".ti. OR instrument*.ab. } \\
\text { 9. measure*.ti. } \\
\text { 10. self report*.ti. OR self report".ab. } \\
\text { 11. } 7 \text { OR } 8 \text { OR } 9 \text { OR } 10 \\
\text { 12. } 6 \text { OR } 11 \\
\text { 13. } 5 \text { AND } 12 \\
\text { 14. Remove duplicates from } 13 \\
\text { 15. Limit } 14 \text { to abstracts } \\
\text { 16. Limit } 15 \text { to English language }\end{array}$ \\
\hline
\end{tabular}

NOTE: Search strategy as conducted in Ovid Medline.

Abbreviations: ab, abstract; CINAHL, Cumulative Index to Nursing and Allied Health Literature; exp, term explosion; mp, free text search for a term; PBSC, Psychology and Behavioral Sciences Collection; ti, title. 


\begin{tabular}{|c|c|c|c|}
\hline $\begin{array}{c}\text { Author and Publication } \\
\text { Year }\end{array}$ & Intervention PROM(s) & Outcome Assessment PROM(s)* & $\begin{array}{c}\text { Same Intervention/Outcome } \\
\text { PROM(s) }\end{array}$ \\
\hline Berry et al, ${ }^{17} 2011$ & $\begin{array}{l}\text { SDS } \\
\text { EORTC QLQ-C30 } \\
\text { Pain scale } \\
\text { PHQ-9 } \\
\text { SSS }\end{array}$ & $\begin{array}{l}\text { Audio-recorded consultations } \\
\text { Author-developed questionnaire regarding clinic visit } \\
\text { duration; clinician evaluation of the intervention }\end{array}$ & No \\
\hline Boyes et al, ${ }^{18} 2006$ & $\begin{array}{l}\text { Physical symptoms scales } \\
\text { HADS } \\
\text { SCNS-SF31 }\end{array}$ & $\begin{array}{l}\text { Physical symptoms scales } \\
\text { HADS } \\
\text { SCNS-SF31 } \\
\text { Patient/clinician acceptability survey }\end{array}$ & Yes, plus additional PROMs \\
\hline Braeken et al, ${ }^{19} 2011$ & SIPP & $\begin{array}{l}\text { Medical records } \\
\text { Intervention evaluation inventories }\end{array}$ & No \\
\hline Carlson et al, ${ }^{20} 2010$ & $\begin{array}{l}\text { DT and problem list } \\
\text { PSSCAN part C }\end{array}$ & $\begin{array}{l}\text { DT and problem list } \\
\text { PSSCAN part C }\end{array}$ & Yes \\
\hline Cleeland et al, ${ }^{40} 2011$ & MDASI & $\begin{array}{l}\text { MDASI } \\
\text { Author-developed form for patient evaluation of the } \\
\text { intervention }\end{array}$ & Yes \\
\hline Detmar et al, ${ }^{21} 2002$ & EORTC OLQ-C30 & $\begin{array}{l}\text { Audio-recorded consultations } \\
\text { COOP } \\
\text { WONCA } \\
\text { Medical records } \\
\text { Author-developed fatigue scale } \\
\text { Patient Satisfaction Questionnaire C } \\
\text { Physician satisfaction with communication } \\
\text { SF-36 } \\
\text { Patient/physician evaluation of the intervention } \\
\text { survey }\end{array}$ & No \\
\hline Ganz et al, ${ }^{22} 2000$ & $\begin{array}{l}\text { Daily diary symptom cards } \\
\text { CARES (sexual summary scale) }\end{array}$ & $\begin{array}{l}\text { Daily diary symptom cards } \\
\text { CARES (sexual summary scale) } \\
\text { RAND Vitality Scale }\end{array}$ & Yes, plus additional PROMs \\
\hline Girgis et al, ${ }^{23} 2009$ & $\begin{array}{l}\text { HADS } \\
\text { EORTC QLQ-C30 } \\
\text { SCNS-SF34 } \\
\text { NA-ACP }\end{array}$ & $\begin{array}{l}\text { HADS } \\
\text { EORTC QLQ-C30 } \\
\text { SCNS-SF34 } \\
\text { NA-ACP } \\
\text { Patient perceptions of improved communication }\end{array}$ & Yes, plus additional PROMs \\
\hline Hilarius et $\mathrm{al}^{24} 2008$ & $\begin{array}{l}\text { EORTC QLC-C30 } \\
\text { EORTC LC13 } \\
\text { EORTC BR23 } \\
\text { EORTC CR38 }\end{array}$ & $\begin{array}{l}\text { Self-report communication questionnaire } \\
\text { COOP } \\
\text { WONCA } \\
\text { Chart audit } \\
\text { PSQ-II } \\
\text { SF-36 } \\
\text { FACT-L/C/BCS } \\
\text { Patient/nurse evaluation of the intervention } \\
\text { questionnaire }\end{array}$ & No \\
\hline Hoekstra et al, ${ }^{25} 2006$ & The Symptom Monitor & The Symptom Monitor & Yes \\
\hline Kearney et al, ${ }^{41} 2009$ & $\begin{array}{l}\text { Author-developed symptom } \\
\text { questionnaire integrating the } \\
\text { CTCAE grading system and the } \\
\text { CSAS (electronic version) }\end{array}$ & $\begin{array}{l}\text { Author-developed symptom questionnaire } \\
\text { integrating the CTCAE grading system and the } \\
\text { CSAS (paper-based version) }\end{array}$ & Yes \\
\hline $\begin{array}{l}\text { Klinkhammer-Schalke et } \\
\quad \text { al }^{26}{ }^{26} 2012\end{array}$ & $\begin{array}{l}\text { EORTC OLC-C30 } \\
\text { EORTC BR23 }\end{array}$ & $\begin{array}{l}\text { EORTC QLC-C30 } \\
\text { EORTC BR23 } \\
\text { Medical records }\end{array}$ & Yes, plus additional PROMs \\
\hline Kornblith et al, ${ }^{42} 2006$ & $\begin{array}{l}\text { HADS } \\
\text { EORTC QLQ-C30 } \\
\text { MOS-SSS }\end{array}$ & $\begin{array}{l}\text { HADS } \\
\text { EORTC QLQ-C30 } \\
\text { MOS-SSS } \\
\text { GDS-SF } \\
\text { OARSQ, physical health subscale } \\
\text { Utilization of mental health and psychosocial } \\
\quad \text { services scale } \\
\text { GSRE } \\
\text { Patient satisfaction with research program }\end{array}$ & Yes, plus additional PROMs \\
\hline \multicolumn{4}{|c|}{ (continued on following page) } \\
\hline
\end{tabular}


Table A2. Intervention and Outcome Assessment PROMs Used in the 24 Studies Reviewed ( $n=26$ articles) (continued)

\begin{tabular}{|c|c|c|c|}
\hline $\begin{array}{c}\text { Author and Publication } \\
\text { Year }\end{array}$ & Intervention PROM(s) & Outcome Assessment PROM(s)* & $\begin{array}{c}\text { Same Intervention/Outcome } \\
\text { PROM(s) }\end{array}$ \\
\hline Maunsell et al, ${ }^{27} 1996$ & GHO-20 & $\begin{array}{l}\text { GHQ-20 } \\
\text { Social Support Questionnaire } \\
\text { LES } \\
\text { LWMAT } \\
\text { PSI } \\
\text { Perceptions of health and worries about health } \\
\text { Number of visits to HP } \\
\text { Medical records }\end{array}$ & Yes, plus additional PROMs \\
\hline McLachlan et $\mathrm{al}^{28} 2001$ & $\begin{array}{l}\text { CNQ-SF } \\
\text { EORTC QLQ-C30 } \\
\text { BDI-SF }\end{array}$ & $\begin{array}{l}\text { CNQ-SF } \\
\text { EORTC QLQ-C30 } \\
\text { BDI-SF } \\
\text { Patient satisfaction survey }\end{array}$ & Yes, plus additional PROMs \\
\hline Mills et $\mathrm{al}^{29} 2009$ & $\begin{array}{l}\text { EORTC OLQ-C30 } \\
\text { EORTC LC13 }\end{array}$ & $\begin{array}{l}\text { FACT-L TOI subscale } \\
\text { PQLI } \\
\text { Utilization of diary } \\
\text { Patient/clinician communication checklist } \\
\text { Patient satisfaction with care survey }\end{array}$ & No \\
\hline Nicklasson et al, ${ }^{30} 2013$ & $\begin{array}{l}\text { EORTC QLQ-C30 } \\
\text { EORTC LC13 }\end{array}$ & $\begin{array}{l}\text { Audio-recorded consultations } \\
\text { Medical records }\end{array}$ & No \\
\hline $\begin{array}{l}\text { Rosenbloom et al, } \\
\quad 2007\end{array}$ & FACT-G & $\begin{array}{l}\text { FLIC } \\
\text { Brief POMS-17 } \\
\text { PSQ-III } \\
\text { Clinical treatment changes survey }\end{array}$ & No \\
\hline Ruland et $\mathrm{al}^{32} 2010$ & Choice ITPA & $\begin{array}{l}\text { Choice ITPA } \\
\text { Chart audit }\end{array}$ & Yes, plus additional PROMs \\
\hline Sarna, ${ }^{33} 1998$ & SDS & SDS & Yes \\
\hline Taenzer et al, ${ }^{34} 2000$ & EORTC QLQ-C30 & $\begin{array}{l}\text { PDIS } \\
\text { Exit interview } \\
\text { Medical record audit }\end{array}$ & No \\
\hline Takeuchi et al, 2011 & $\begin{array}{l}\text { EORTC QLQ-C30 } \\
\text { HADS }\end{array}$ & Audio-recorded consultations & No \\
\hline Thewes et al, ${ }^{36} 2009$ & $\begin{array}{l}\text { DT } \\
\text { SPHERE-Short }\end{array}$ & $\begin{array}{l}\text { Medical records } \\
\text { SCNS-SF34 } \\
\text { Satisfaction with intervention, Likert scales }\end{array}$ & No \\
\hline $\begin{array}{l}\text { Trowbridge et al, } \\
1997\end{array}$ & Pain inventories & $\begin{array}{l}\text { Pain inventories } \\
\text { PMI } \\
\text { Chart audit }\end{array}$ & Yes, plus additional PROMs \\
\hline Velikova et al, ${ }^{38} 2004$ & $\begin{array}{l}\text { EORTC QLQ-C30 } \\
\text { HADS }\end{array}$ & $\begin{array}{l}\text { Audio-recorded consultations } \\
\text { FACT-G } \\
\text { Physician use of QoL information checklist }\end{array}$ & No \\
\hline Velikova et al, ${ }^{39} 2010$ & $\begin{array}{l}\text { EORTC QLQ-C30 } \\
\text { HADS }\end{array}$ & $\begin{array}{l}\text { MCQ } \\
\text { Satisfaction with care, single-item scales } \\
\text { Intervention evaluation questionnaires }\end{array}$ & No \\
\hline \multicolumn{4}{|c|}{ 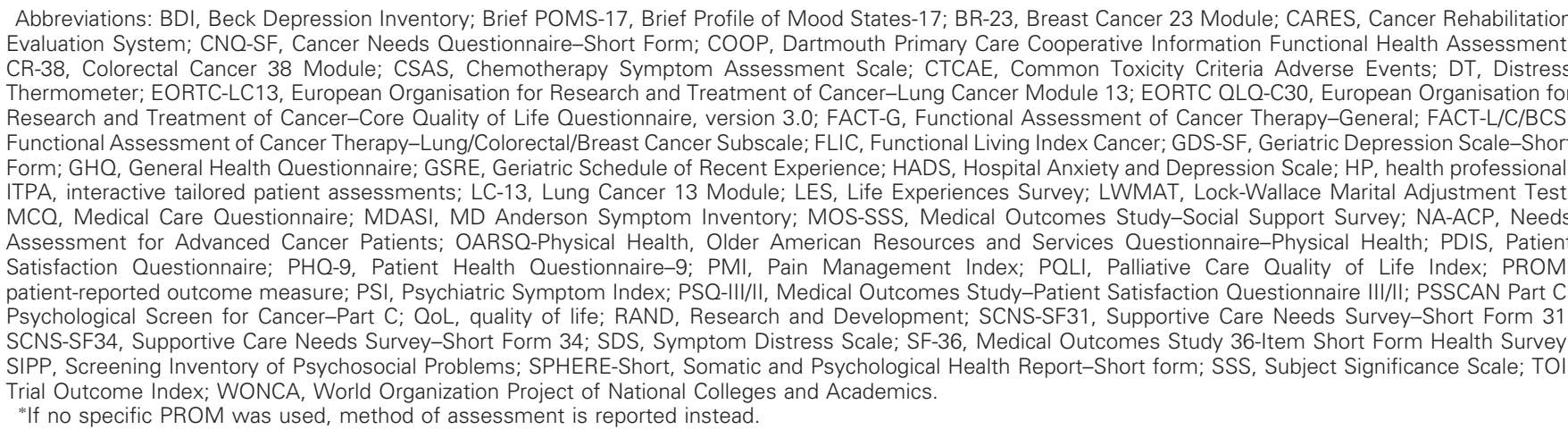 } \\
\hline
\end{tabular}




\begin{tabular}{|c|c|c|c|}
\hline Outcome & $\mathrm{ES}(d)$ & $95 \% \mathrm{Cl}^{*} \dagger$ & Effect Characterization $\neq$ \\
\hline Menopausal symptom distress & -1.18 & -1.68 to $-0.67^{22}$ & + \\
\hline \multicolumn{4}{|l|}{ Prevalence } \\
\hline Anxiety & -0.07 & -0.41 to $0.27^{23}$ & \pm \\
\hline Depression & -0.15 & -0.73 to $0.43^{23}$ & \pm \\
\hline Overall supportive care needs & $\begin{array}{l}-0.20 \\
0.58^{36}\end{array}$ & -0.46 to $0.06^{23}$ & $\begin{array}{l} \pm \\
+\end{array}$ \\
\hline \multicolumn{4}{|l|}{ Need for help } \\
\hline Psychological needs & $\begin{array}{l}-0.16 \\
0.50^{36}\end{array}$ & -0.73 to $0.40^{18}$ & $\begin{array}{l} \pm \\
+\end{array}$ \\
\hline Information needs & $\begin{array}{l}-0.29 \\
0.53^{36}\end{array}$ & -0.86 to $0.28^{18}$ & $\begin{array}{l} \pm \\
+\end{array}$ \\
\hline Patient care and support & -0.47 & -1.05 to $0.10^{18}$ & \pm \\
\hline Physical and daily living & $\begin{array}{l}-0.34 \\
0.46^{36}\end{array}$ & -0.91 to $0.24^{18}$ & $\begin{array}{l} \pm \\
\pm\end{array}$ \\
\hline Sexual functioning & -0.49 & -0.96 to $-0.02^{22}$ & + \\
\hline \multicolumn{4}{|l|}{ QoL } \\
\hline Role functioning & $\begin{array}{l}-0.04 \\
-0.12\end{array}$ & $\begin{array}{l}-0.26 \text { to } 0.19^{23} \\
-0.40 \text { to } 0.16^{21}\end{array}$ & $\begin{array}{l} \pm \\
\pm\end{array}$ \\
\hline Emotional/psychological functioning & $\begin{array}{l}-0.18 \\
-0.11^{31} \\
-0.20 \\
0.10\end{array}$ & $\begin{array}{l}-0.41 \text { to } 0.05^{23} \\
-0.48 \text { to } 0.07^{21} \\
-0.25 \text { to } 0.44^{42}\end{array}$ & $\begin{array}{l} \pm \\
\pm \\
\pm \\
\pm\end{array}$ \\
\hline Cognitive functioning & -0.05 & -0.27 to $0.18^{23}$ & \pm \\
\hline Social functioning & $\begin{array}{l}-0.01 \\
-0.04^{31} \\
-0.07\end{array}$ & $\begin{array}{l}-0.24 \text { to } 0.22^{23} \\
-0.35 \text { to } 0.21^{21}\end{array}$ & $\begin{array}{l} \pm \\
\pm \\
\pm\end{array}$ \\
\hline Physical functioning & $\begin{array}{l}-0.16 \\
-0.12^{31} \\
-0.04 \\
-0.20\end{array}$ & $\begin{array}{l}-0.39 \text { to } 0.01^{23} \\
-0.32 \text { to } 0.24^{21} \\
-0.55 \text { to } 0.15^{42}\end{array}$ & $\begin{array}{l} \pm \\
\pm \\
\pm \\
\pm\end{array}$ \\
\hline Physical and functional well-being & -0.41 & -0.95 to $0.14^{29}$ & \pm \\
\hline Mental health & -0.10 & -0.38 to $0.18^{21}$ & \pm \\
\hline Vitality & $\begin{array}{r}0.08 \\
-0.08\end{array}$ & $\begin{array}{l}-0.38 \text { to } 0.54^{22} \\
-0.36 \text { to } 0.20^{21}\end{array}$ & $\begin{array}{l} \pm \\
\pm\end{array}$ \\
\hline Bodily pain & -0.07 & -0.35 to $0.21^{21}$ & \pm \\
\hline Nausea & $-0.16^{31}$ & & \pm \\
\hline Hardship owing to cancer & $-0.05^{31}$ & & \pm \\
\hline Overall QoL & $\begin{array}{l}-0.05 \\
-0.14^{31} \\
-0.59 \\
-0.35 \\
-0.04\end{array}$ & $\begin{array}{l}-0.28 \text { to } 0.17^{23} \\
-1.16 \text { to }-0.01^{29} \\
-0.70 \text { to }-0.001^{26} \\
-0.38 \text { to } 0.31^{42}\end{array}$ & $\begin{array}{l} \pm \\
\pm \\
+ \\
+ \\
\pm\end{array}$ \\
\hline \multicolumn{4}{|l|}{ Severity } \\
\hline Fatigue & $\begin{array}{l}-0.37 \\
-0.25\end{array}$ & $\begin{array}{l}-0.77 \text { to } 0.04^{25} \\
-0.63 \text { to } 0.12^{41}\end{array}$ & $\begin{array}{l} \pm \\
\pm\end{array}$ \\
\hline Pain & 0.04 & -0.36 to $0.44^{25}$ & \pm \\
\hline Lack of appetite & -0.04 & -0.44 to $0.36^{25}$ & \pm \\
\hline Shortness of breath & 0.05 & -0.35 to $0.45^{25}$ & \pm \\
\hline Sore mouth/throat & 0.32 & -0.05 to $0.69^{41}$ & \pm \\
\hline Coughing & -0.37 & -0.77 to $0.03^{25}$ & \pm \\
\hline Sleeplessness & -0.31 & -0.71 to $0.09^{25}$ & \pm \\
\hline Hand-foot syndrome & 0.42 & 0.05 to $0.79^{41}$ & - \\
\hline Nausea & $\begin{array}{l}-0.44 \\
-0.18\end{array}$ & $\begin{array}{l}-0.84 \text { to } 0.04^{25} \\
-0.55 \text { to } 0.20^{41}\end{array}$ & $\begin{array}{l} \pm \\
\pm\end{array}$ \\
\hline Constipation & 0.24 & -0.16 to $0.64^{25}$ & \pm \\
\hline Diarrhea & $\begin{array}{l}0.0 \\
0.06\end{array}$ & $\begin{array}{l}-0.40 \text { to } 0.40^{25} \\
-0.32 \text { to } 0.43^{41}\end{array}$ & $\begin{array}{l} \pm \\
\pm\end{array}$ \\
\hline Vomiting & $\begin{array}{l}0.33 \\
0.01\end{array}$ & $\begin{array}{l}-0.07 \text { to } 0.73^{25} \\
-0.36 \text { to } 0.38^{41}\end{array}$ & $\begin{array}{l}- \\
\pm \\
\pm\end{array}$ \\
\hline Anxiety & $\begin{array}{l}-0.09 \\
-0.05^{20} \\
-0.30\end{array}$ & $\begin{array}{l}-0.65 \text { to } 0.48^{18} \\
-0.65 \text { to } 0.04^{42}\end{array}$ & $\begin{array}{l} \pm \\
\pm \\
\pm \\
\pm\end{array}$ \\
\hline & (cont & ge) & \\
\hline
\end{tabular}




\begin{tabular}{|c|c|c|c|}
\hline Outcome & $\mathrm{ES}(d)$ & $95 \% \mathrm{Cl}^{*} \dagger$ & Effect Characterization \\
\hline \multirow[t]{3}{*}{ Depression } & 0.08 & -0.49 to $0.64^{18}$ & \pm \\
\hline & $-0.01^{20}$ & & \pm \\
\hline & -0.15 & -0.49 to $0.20^{42}$ & \pm \\
\hline \multirow[t]{2}{*}{ Psychological distress } & -0.09 & -0.34 to $0.16^{27}$ & \pm \\
\hline & -0.42 & -0.76 to $-0.07^{42}$ & + \\
\hline \multicolumn{4}{|l|}{ Prevalence } \\
\hline \multirow[t]{3}{*}{ Fatigue } & -0.07 & -0.62 to $0.47^{25}$ & \pm \\
\hline & -0.29 & -0.60 to $0.02^{18}$ & \pm \\
\hline & $-0.20^{41}$ & & + \\
\hline Pain & -0.33 & -0.78 to $0.12^{25}$ & \pm \\
\hline \multirow[t]{2}{*}{ Lack of appetite } & -0.29 & -0.74 to $0.15^{25}$ & \pm \\
\hline & -0.19 & -0.55 to $0.18^{18}$ & \pm \\
\hline Shortness of breath & -0.06 & -0.50 to $0.38^{25}$ & \pm \\
\hline Coughing & 0.34 & -0.11 to $0.79^{25}$ & \pm \\
\hline Sleeplessness & -0.40 & -0.85 to $0.04^{25}$ & \pm \\
\hline \multirow[t]{3}{*}{ Nausea } & -0.10 & -0.57 to $0.37^{25}$ & \pm \\
\hline & -0.06 & -0.79 to $0.67^{18}$ & \pm \\
\hline & $-0.10^{41}$ & & \pm \\
\hline \multirow[t]{2}{*}{ Constipation } & -0.73 & -1.29 to $-0.17^{25}$ & + \\
\hline & -0.06 & -1.60 to $1.49^{18}$ & \pm \\
\hline \multirow[t]{3}{*}{ Diarrhea } & -0.32 & -0.90 to $0.27^{25}$ & \pm \\
\hline & -0.88 & -2.10 to $0.37^{18}$ & \pm \\
\hline & $0.01^{41}$ & & \pm \\
\hline \multirow[t]{2}{*}{ Vomiting } & -0.98 & -1.83 to $-0.13^{25}$ & + \\
\hline & $-0.05^{41}$ & & \pm \\
\hline Skin rash & -0.06 & -1.60 to $1.49^{18}$ & \pm \\
\hline \multirow[t]{2}{*}{ Sore mouth } & 0.25 & -0.58 to $1.08^{18}$ & \pm \\
\hline & $0.06^{41}$ & & \pm \\
\hline Metallic taste & -0.06 & -1.17 to $1.05^{18}$ & \pm \\
\hline Hot flashes & 0.75 & -0.48 to $1.98^{18}$ & \pm \\
\hline Hand-foot syndrome & $0.23^{41}$ & & + \\
\hline Overall distress & $-0.15^{20}$ & & \pm \\
\hline \multicolumn{4}{|l|}{ Distress } \\
\hline Vomiting & 0.05 & -0.32 to $0.42^{41}$ & \pm \\
\hline Nausea & -0.15 & -0.52 to $0.22^{41}$ & \pm \\
\hline Diarrhea & 0.0 & -0.37 to $0.37^{41}$ & \pm \\
\hline Hand-foot syndrome & 0.35 & -0.02 to $0.72^{41}$ & + \\
\hline Sore mouth/throat & 0.33 & -0.05 to $0.70^{41}$ & \pm \\
\hline Fatigue & -0.31 & -0.69 to $0.06^{41}$ & \pm \\
\hline \multirow[t]{2}{*}{ Overall } & $-0.02^{31}$ & & \pm \\
\hline & $-0.16^{20}$ & & \pm \\
\hline \multirow[t]{2}{*}{ Health status } & -0.01 & -0.34 to $0.33^{27}$ & \pm \\
\hline & 0.0 & -0.34 to $0.34^{42}$ & \\
\hline Worry about health & -0.10 & -0.39 to $0.20^{27}$ & \pm \\
\hline Working during assessment & 0.01 & -0.28 to $0.30^{27}$ & \pm \\
\hline Hours worked per week & -0.05 & -0.30 to $0.20^{27}$ & \pm \\
\hline Household activities performed & -0.08 & -0.33 to $0.17^{27}$ & \pm \\
\hline Engagement in social activities & -0.23 & -0.48 to $0.02^{27}$ & \pm \\
\hline Engagement in leisure activities & 0.14 & -0.11 to $0.39^{27}$ & \pm \\
\hline Engagement in physical activities & -0.02 & -0.27 to $0.23^{27}$ & \pm \\
\hline Marital satisfaction & 0.0 & -0.25 to $0.25^{27}$ & \pm \\
\hline \multicolumn{4}{|c|}{$\begin{array}{l}\text { NOTE. Negative ES denote more favorable outcomes (eg, less severity or better scores) for the intervention group, and vice versa. ES were not calculated for } \\
\text { controlled trials that reported pre-intervention between-group differences in the outcome in question, or where no relevant data were available. Where data were } \\
\text { available, but no such baseline comparisons were performed/stated, baseline scores/percentages were compared using two-tailed independent sample t tests, thus } \\
\text { ensuring that postintervention scores were not a result of preintervention differences. When studies reported results at more than one time point, the final time } \\
\text { point was used, thus ensuring independence of data; hence, each study contributed no more than one ES for a specific outcome. }{ }^{14} \text { For studies with more than one } \\
\text { experimental group, separate ES were calculated if different intervention PROMs were used; however, if the same intervention PROM was used, one ES was } \\
\text { calculated based on pooled experimental versus control effects. If a study indicated that the effect was nonsignificant but no statistics were provided, ES was } \\
\text { entered as zero. } \\
\text { Abbreviations: ES, effect sizes; PROM, patient-reported outcome measure; QoL, quality of life. } \\
\text { "ES calculations were performed only in those studies for which enough data were available. } \\
\text { tWhere no } 95 \% \text { Cls are reported, not enough data were available to calculate them. } \\
\text { fBased on } P \text { values }(P<.05) \text { and direction; }+ \text { favors the intervention group }(P<.05) ;- \text { favors the control group }(P<.05) ; \pm \text { represents } P \geq .05 \text {. }\end{array}$} \\
\hline
\end{tabular}




\begin{tabular}{|c|c|c|c|}
\hline Outcome & $\mathrm{ES}(d)$ & $95 \% \mathrm{Cl}^{*} \dagger$ & Effect Characterization $\neq$ \\
\hline \multicolumn{4}{|l|}{ Action } \\
\hline Enrolled onto medical trial & -0.15 & -0.53 to $0.22^{27}$ & \pm \\
\hline Met with other survivors & -0.14 & -0.41 to $0.14^{27}$ & \pm \\
\hline Participated in patient-support group & -0.02 & -0.47 to $0.43^{27}$ & \pm \\
\hline Consulted treating oncologist & -0.22 & -0.52 to $0.09^{24}$ & \pm \\
\hline Consulted family physician & -0.002 & -0.33 to $0.32^{27}$ & \pm \\
\hline Consulted other physician & -0.10 & -0.38 to $0.18^{27}$ & \pm \\
\hline Had consultation for CAM therapies & -0.18 & -0.54 to $0.19^{27}$ & \pm \\
\hline Had psychiatric/psychological consultation & -0.02 & -0.44 to $0.40^{27}$ & \pm \\
\hline Sought help because of feeling depressed/sad & -0.11 & -0.41 to $0.19^{27}$ & \pm \\
\hline Had a confidant & -0.27 & -0.67 to $0.13^{27}$ & \pm \\
\hline Participated in relaxation activities & -0.05 & -0.43 to $0.32^{27}$ & \pm \\
\hline Made dietary changes & 0.13 & -0.14 to $0.41^{27}$ & \pm \\
\hline \multicolumn{4}{|l|}{ Discussed } \\
\hline \multirow[t]{4}{*}{ Nausea/vomiting } & -0.06 & -0.26 to $0.14^{17}$ & \pm \\
\hline & 0.22 & -0.08 to $0.52^{24}$ & \pm \\
\hline & $0.02^{38}$ & & \pm \\
\hline & -0.07 & -0.41 to $0.27^{21}$ & \pm \\
\hline \multirow[t]{5}{*}{ Appetite } & -0.06 & -0.24 to $0.13^{17}$ & \pm \\
\hline & -0.09 & -0.41 to $0.22^{24}$ & \pm \\
\hline & $-0.40^{38}$ & & + \\
\hline & -0.34 & -0.65 to $-0.03^{30}$ & + \\
\hline & 0.06 & -0.25 to $0.37^{21}$ & \pm \\
\hline \multirow[t]{4}{*}{ Insomnia/sleep problems } & -0.05 & -0.23 to $0.13^{17}$ & \pm \\
\hline & -0.66 & -1.00 to $-0.32^{24}$ & + \\
\hline & $-0.64^{38}$ & & + \\
\hline & -0.13 & -0.50 to $0.24^{21}$ & \pm \\
\hline \multirow[t]{5}{*}{ Pain } & 0.02 & -0.16 to $0.19^{17}$ & \pm \\
\hline & -0.10 & -0.39 to $0.20^{24}$ & \pm \\
\hline & $-0.01^{38}$ & & \pm \\
\hline & -0.05 & -0.36 to $0.25^{30}$ & \pm \\
\hline & -0.30 & -0.62 to $0.03^{21}$ & \pm \\
\hline \multirow[t]{5}{*}{ Fatigue } & 0.0 & -0.19 to $0.19^{17}$ & \pm \\
\hline & -0.13 & -0.43 to $0.17^{24}$ & \pm \\
\hline & $-0.34^{38}$ & & \pm \\
\hline & -0.06 & -0.36 to $0.25^{30}$ & \pm \\
\hline & -0.38 & -0.69 to $-0.07^{21}$ & + \\
\hline Bowel pattern & 0.14 & -0.05 to $0.33^{17}$ & \pm \\
\hline Constipation & -0.40 & -0.72 to $-0.08^{24}$ & + \\
\hline Diarrhea & -0.67 & -1.04 to $-0.30^{24}$ & + \\
\hline Concentration & -0.29 & -0.64 to $0.07^{17}$ & \pm \\
\hline Appearance & 0.19 & -0.07 to $0.45^{17}$ & \pm \\
\hline Impact on sex & -0.58 & -0.99 to $-0.17^{17}$ & + \\
\hline \multirow[t]{5}{*}{ Breathing/dyspnea } & 0.01 & -0.18 to $0.19^{17}$ & \pm \\
\hline & -0.77 & -1.22 to $-0.33^{24}$ & + \\
\hline & $-0.15^{38}$ & & \pm \\
\hline & -0.18 & -0.48 to $0.13^{30}$ & \pm \\
\hline & -0.40 & -0.82 to $0.02^{21}$ & \pm \\
\hline Outlook & -0.05 & -0.24 to $0.15^{17}$ & \pm \\
\hline Cough & -0.05 & -0.24 to $0.14^{17}$ & \pm \\
\hline Fever/chills & -0.03 & -0.21 to $0.15^{17}$ & \pm \\
\hline Depression & -0.12 & -0.36 to $0.13^{17}$ & \pm \\
\hline Suicidal ideation & -0.26 & -0.89 to $0.36^{17}$ & \pm \\
\hline \multirow{2}{*}{ Symptoms of illness } & -0.07 & -0.38 to $0.23^{30}$ & \pm \\
\hline & 0.02 & -0.52 to $0.56^{29}$ & \pm \\
\hline \multirow[t]{7}{*}{ Physical functioning } & 0.03 & -0.15 to $0.21^{17}$ & \pm \\
\hline & 0.26 & -0.10 to $0.63^{24}$ & \pm \\
\hline & $-0.21^{38}$ & & \pm \\
\hline & -0.18 & -0.48 to $0.13^{30}$ & \pm \\
\hline & -0.98 & -1.31 to $-0.64^{21}$ & + \\
\hline & -0.05 & -0.26 to $0.17^{19}$ & \pm \\
\hline & \multicolumn{3}{|c|}{ (continued on following page) } \\
\hline
\end{tabular}




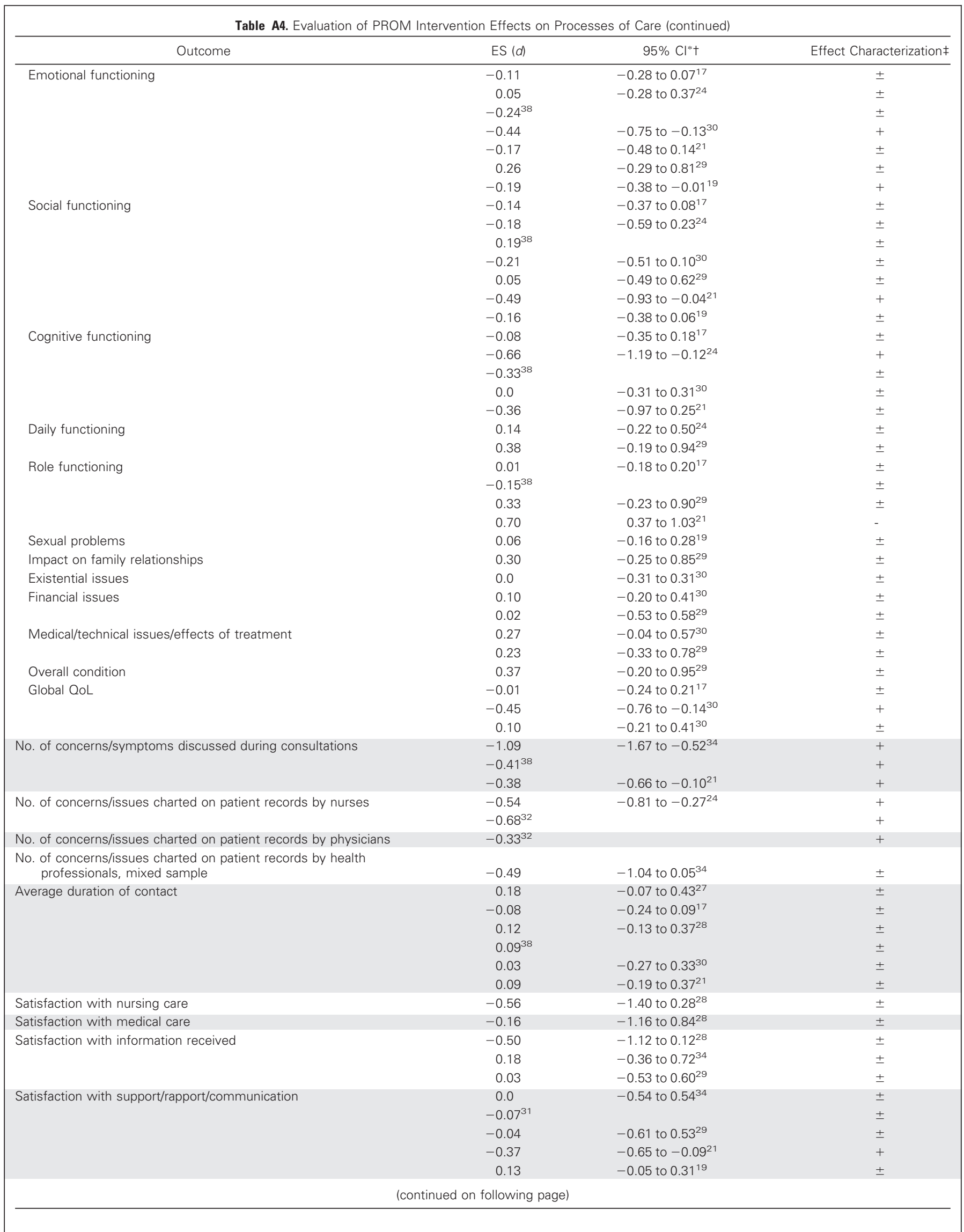




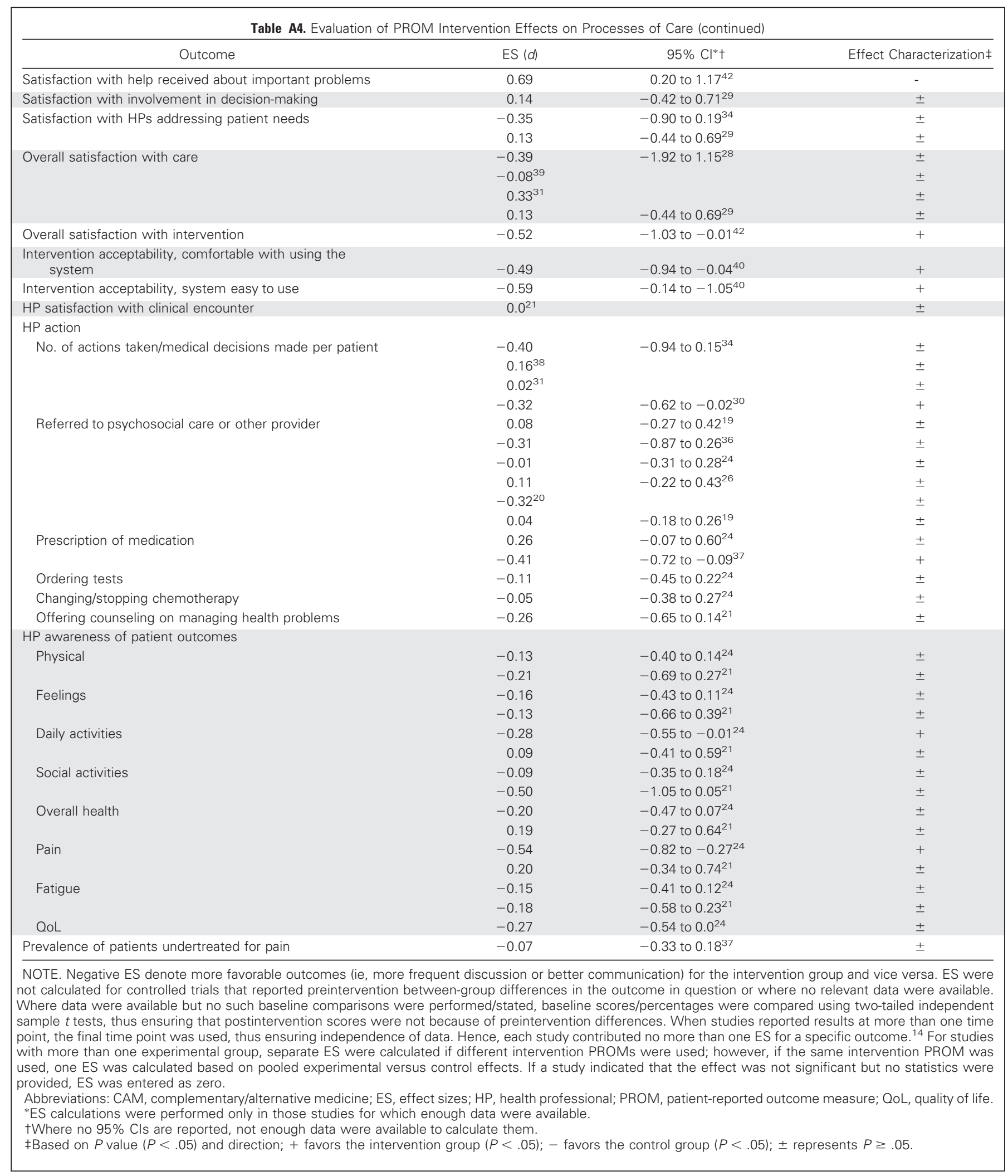


Table A5. Evaluation of PROM Intervention Effects on Health Service Outcomes

\begin{tabular}{|c|c|c|c|}
\hline Outcome & $\mathrm{ES}(d)$ & $95 \% \mathrm{Cl}^{*}$ & Effect Characterization $†$ \\
\hline Patient use of psychological referrals & -0.10 & -1.02 to $0.82^{22}$ & \pm \\
\hline Self-referrals & -0.20 & -0.44 to $0.04^{20}$ & \pm \\
\hline \multirow[t]{2}{*}{ Patient contacts with health professional } & -0.85 & -1.10 to $-0.59^{27}$ & + \\
\hline & -0.15 & -0.45 to $0.15^{30}$ & \pm \\
\hline Patient use of mental health services & 0.18 & -0.45 to $0.82^{42}$ & \pm \\
\hline \multicolumn{4}{|c|}{$\begin{array}{l}\text { NOTE. Negative effect sizes denote more favorable outcomes (eg, more frequent use of service or more contacts) for the intervention group and vice versa. ES } \\
\text { were not calculated for controlled trials that reported preintervention between-group differences in the outcome in question or where no relevant data were available. } \\
\text { Where data were available but no such baseline comparisons were performed or stated, baseline scores/percentages were compared using two-tailed independent } \\
\text { sample } t \text { tests, thus ensuring that postintervention scores were not because of preintervention differences. When studies reported results at more than one time } \\
\text { point, the final time point was used, thus ensuring independence of data. Hence, each study contributed no more than one ES for a specific outcome. }{ }^{14} \text { For studies } \\
\text { with more than one experimental group, separate ES were calculated if different intervention PROMs were used; however, if the same intervention PROM was } \\
\text { used, one ES was calculated based on pooled experimental versus control effects. If a study indicated that the effect was nonsignificant but no statistics were } \\
\text { provided, ES was entered as zero. } \\
\text { Abbreviations: ES, effect size; PROM, patient-reported outcome measure. } \\
{ }^{*} \text { ES calculations were performed only in those studies for which enough data were available. } \\
\text { †Based on } P \text { value }(P<.05) \text { and direction; }+(P<.05 \text { favors intervention group); }-P<.05 \text { favors control group); } \pm(P \geq .05) \text {. }\end{array}$} \\
\hline
\end{tabular}

